\title{
Experimental Evaluation of the Mechanical Properties of Steel Reinforcement at Elevated Temperature
}

\begin{abstract}
This paper describes an experimental investigation into the influence of elevated temperatures on the mechanical properties of steel reinforcement. The study includes tests carried out under ambient temperature as well as steady-state and transient elevated temperature conditions. A complementary study, in which the residual post-cooling properties of reinforcing bars were examined, is also described. The tests focused on assessing the performance of 6 and $8 \mathrm{~mm}$ diameters, although $10 \mathrm{~mm}$ bars were also considered in some cases. The specimens included both plain and deformed bars. After providing an outline of the experimental set-up and loading procedures, a detailed account of the test results is presented and discussed. Apart from the evaluation of stress-strain response and the degradation of stiffness and strength properties, particular emphasis is given to assessing the influence of temperature on enhancing the ductility of reinforcement. The findings of this study have direct implications on procedures used for predicting the ultimate behaviour of structural floor elements and assemblages during, and following, exposure to elevated temperatures.
\end{abstract}

\section{Introduction}

The structural response of buildings to fire conditions has been the focus of intensive research activity in recent years. For composite steel/concrete buildings, this has been driven by the motivation to achieve more cost-effective designs and, more generally, by the need to attain a greater understanding of the underlying behavioural mechanisms that occur in fire. As a result, there has been an increasing recognition of the benefits of employing performance-based fire design, in comparison with prescriptive approaches which are based on unrealistic idealisations.

The fire tests carried out on the full-scale eight-story composite steel/concrete building at Cardington [1, 2] generated significant research interest and provided considerable insights into the actual response characteristics under fire conditions. The experimental 
findings were also complemented by numerical simulations and analytical investigations [e.g. 3-6] which provided additional understanding of the main behavioural characteristics. Importantly, the significant role played by the composite floor slab under fire conditions was demonstrated. It was shown that the floor slab continues to support gravity loading through membrane action, even after the loss of the deck and secondary steel beams. This enables alternative load paths and redistributions to develop even after conventional strength limits have been reached.

Reliance on the secondary load-carrying mechanisms in slabs needs to be supported by detailed assessment of the limiting failure criteria. Apart from compressive mechanisms that may occur in the slab, a key failure condition is related to fracture of the steel reinforcement in tension. Due to the early loss of the steel deck in fire, the remaining part of the composite slab behaves as a concrete member with relatively light reinforcement. Depending on the location of the reinforcing bars within the slab depth, as well as the specific fire scenario, temperatures of up to $600^{\circ} \mathrm{C}$ can typically develop in the reinforcement. However, assessment of the failure conditions associated with reinforcement fracture under these conditions is a complex issue that is influenced by a number of inter-related material and geometric parameters. To this end, fundamental analytical approaches have recently been proposed which predict the level of deformation and load corresponding to failure by reinforcement fracture at elevated temperature [7-10]. Nevertheless, the reliability of these approaches is directly dependent on the availability of studies which provide the necessary information about the characteristics of key material properties at expected levels of elevated temperature.

Whilst ample data is available in the literature on the influence of elevated temperature on the main properties of concrete and steel materials, there is a relative lack of information on the ductility of steel reinforcement. Accordingly, this paper presents the results and observations from an experimental investigation into the effect of elevated temperature on reinforcing bars tested to fracture. The test series has been completed as part of a wider study dealing with the ultimate behaviour of floor slabs under idealised fire conditions. The paper examines the behaviour of both ribbed and plain reinforcing bars of relatively small diameter at elevated temperature as well as in terms of post-fire residual properties. After providing a brief background on the typical characteristics of steel reinforcement at elevated temperature, a description of the experimental set-up and 
instrumentation is given. This is followed by a discussion of the main results and observations from the tests, including comparisons with information available from current design guidelines, where appropriate.

\section{Temperature-Dependant Properties}

The reduction in stiffness and strength of steel reinforcement with increasing temperature depends on the manufacturing process of the reinforcing bars [11-13]. For example, in Eurocode 2 [13] an idealised stress-strain relationship is assumed as depicted in Figure 1. A linear relationship is initially considered followed by an elliptical representation until the maximum stress is achieved at a strain of $\varepsilon_{s y, \theta}$, after which a constant strength is assumed between $\varepsilon_{s y, \theta}$ and $\varepsilon_{s t, \theta}$. The main parameters related to stiffness and strength (i.e. $E_{s, \theta}, f_{s p, \theta}$ and $f_{s y, \theta}$ ) are assigned reduction factors for increasing temperatures. These reduction factors are discussed in subsequent parts of the paper. More importantly, in terms of ductility, the Eurocode approach considers $\varepsilon_{s y, \theta}$, $\varepsilon_{s t, \theta}$ and $\varepsilon_{s u, \theta}$ as constant values irrespective of the temperature; these are stipulated as $0.02,0.15$ and 0.2 , respectively (for Class $\mathrm{B}$ and $\mathrm{C}$ reinforcement) and 0.02, 0.05 and 0.1 , respectively (for Class A reinforcement). Accordingly, it is assumed that the ductility of reinforcement is unaffected by the level of temperature, an assumption which is examined in more detail in the experimental investigation described in this paper.

It should be noted that the above discussion is related to 'stress-induced strain' or 'mechanical strain'. Clearly, the total deformation exhibited by the reinforcement at elevated temperature also includes the influence of thermal strains due to thermal expansion. Thermal strain is recovered after cooling, and a typical representation of the relationship between thermal strain and temperature is depicted in Figure 2 [13]. For the purpose of simple calculation models, design guides recommend the use of a constant value of about $14 \times 10^{-6} /{ }^{\circ} \mathrm{C}$ for the coefficient of thermal expansion.

Steel may also exhibit creep strain effects if it is exposed to a combination of elevated temperature and high stress over time. This has been shown to be relatively insignificant up to around $400-500^{\circ} \mathrm{C}[11]$. Above these temperatures, the deformation increases with time even if the temperature and stresses remain unchanged, although the process proceeds more rapidly if either of these properties increases. Detailed calculations of 
creep-related strain are arduous and hence, it tends to be implicitly accounted for in the stress-strain idealisations used in analysis. In any case, it has been shown [14] that within a realistic range of heating rates that are representative of real fires (i.e. between $5^{\circ} \mathrm{C} / \mathrm{min}$ for a member with heavy insulation to $50^{\circ} \mathrm{C} / \mathrm{min}$ for a non-insulated member), the development of creep strain is insignificant.

As mentioned previously, the experimental study described in this paper focuses on assessing the stress-strain behaviour of deformed and plain bars of relatively small diameters that may be typically employed in composite slabs. The tests consider the behaviour at temperature levels that may be reached by the reinforcement within the cross-section of composite slabs, as well as the residual properties after cooling. Particular emphasis is given to the influence of temperature on ductility, in terms of ultimate strain at fracture, which is critical for the reliable assessment of the performance of structural members under fire conditions.

\section{Experimental Response at Ambient Temperature}

As noted before, the main objectives of the material tests were to examine the variation in key properties of steel reinforcement with temperature, as well as the residual properties after cooling. In order to assess the behaviour of steel reinforcement of different characteristics, five bar configurations were considered, incorporating variation in diameter $(6,8$ and $10 \mathrm{~mm})$, manufacturing process (hot-rolled and coldworked) and surface condition (plain and deformed). In this study, the following designations are used for the different bars: P6 for plain $6 \mathrm{~mm}$ bars, D6 for deformed $6 \mathrm{~mm}$ bars, D8 for deformed $8 \mathrm{~mm}$ bars, P10 for plain $10 \mathrm{~mm}$ bars, and D10 for Deformed $10 \mathrm{~mm}$ bars. P6, P10 and D10 bars were specified as hot-rolled whereas D6 and D8 were cold-worked.

The experimental investigation included (i) tensile tests at ambient temperature; (ii) steady-state elevated temperature tests; (iii) transient elevated temperature tests at a constant load; and (iv) steady-state tests for assessing residual properties. Before conducting the elevated temperature tests, it was firstly important to ascertain the properties of the selected reinforcement configurations at ambient conditions. This section therefore outlines the results obtained from the ambient tests whilst subsequent sections describe the elevated temperature tests. 
Three ambient tensile tests were carried out for each bar-type, in accordance with EN ISO 15630-1 [15], using an Instron testing machine operated in displacement control, at a rate of $4 \mathrm{~mm} / \mathrm{min}$. Each specimen was cut to an overall length of $1000 \mathrm{~mm}$, out of which $200 \mathrm{~mm}$ was used for gripping at the two ends. A carefully-selected measuringdevice was employed to measure extension, as shown in Figure 3, which was capable of capturing the full stress-strain response over a gauge length of $100 \mathrm{~mm}$. Typical stressstrain relationships obtained for the five reinforcement configurations are presented in Figure 4. In addition, the key mechanical characteristics are summarised in Table 1

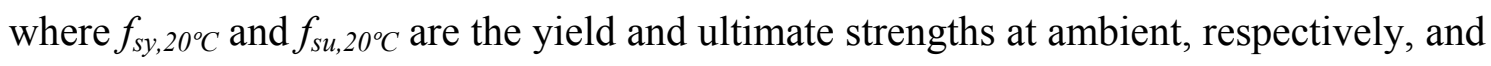
$\varepsilon_{s u, 20^{\circ} \mathrm{C}}$ is the corresponding ultimate strain, measured through the extensometer. The values given in the table are the average obtained from at least three specimens for each type of bar. The coefficient of variation was lower than 0.03 for both $f_{s y, 20^{\circ} \mathrm{C}}$ and $f_{s u, 20^{\circ} \mathrm{C}}$ and lower than 0.06 for $\varepsilon_{s u, 20^{\circ} \mathrm{C}}$, in all cases.

Evidently, the shape of the stress-strain response is directly influenced by the manufacturing process employed. The hot-rolled reinforcement (P6, P10 and D10) exhibited a clear yield plateau from which $f_{s y, 20^{\circ} \mathrm{C}}$ could be easily distinguished. In contrast, both D6 and D8 bars were cold-worked and therefore displayed a more continuous stress-strain relationship; accordingly, in these cases, a $0.2 \%$ proof stress was employed to define the yield point. In terms of the reinforcement categories used in Eurocodes and other guides, the values given in Table 1 indicate that D6 falls within the definition of Class 'A' bars, D8 conforms to the characteristics of Class 'B', while the other three bar-types satisfy the requirements of Class ' $\mathrm{C}$ '.

\section{Steady-State Elevated Temperature Tests}

The set-up used in the elevated temperature tests is illustrated in Figures 5 and 6. A hydraulic testing machine was utilised, and heating was applied using an electric furnace, as shown in Figure 5. The total length of the reinforcement specimen was 1000 $\mathrm{mm}$ with a heated segment of $325 \mathrm{~mm}$. As well as overall load and displacement readings, the extension in the heated part of the bar was measured using the arrangement shown in Figure 6. It should be noted however that at relatively high levels of strain, it was difficult to prevent some slippage within the strain-measuring set-up, particularly for the $6 \mathrm{~mm}$ bars, as the cross-sectional area of the small diameter bars reduced. Therefore, the reliability of strain measurements at relatively high deformation 
levels, approaching fracture, required additional validation. In view of this and in order to facilitate the measurement of ultimate strain after cooling, the reinforcement specimens were marked clearly at $30 \mathrm{~mm}$ intervals prior to testing. Thermocouples were used to measure the temperature inside the furnace and on the surface of the specimen. In the steady-state tests, the temperature was kept constant while the load was increased gradually. Although a number of transient temperature tests were carried out for verification as discussed in Section 5, a larger number of steady-state tests were performed owing to their relative simplicity in terms of execution and interpretation,

The stress-strain relationship at a given temperature $\theta$, is defined herein by four key parameters: (i) the slope in the linear-elastic range $\left(E_{s, \theta}\right)$, (ii) the proportional limit $\left(f_{s p, \theta}\right)$ after which non-linear behaviour is exhibited, (iii) the ultimate stress $\left(f_{s u, \theta}\right)$ corresponding to the maximum capacity of the bars; and (iv) the ultimate mechanical strain at fracture $\left(\varepsilon_{s u, \theta}\right)$. The 'yield stress', is notably absent from this list. Whilst this term is relatively straight-forward to establish at ambient temperature, in addition to the reduction in both stiffness and strength parameters the behaviour becomes increasingly non-linear with elevated temperature. Therefore, the yield strength cannot be determined without a predefined yield strain criterion. This is typically selected between $0.1-0.2 \%$ in ambient conditions and $1-2 \%$ at elevated temperature, although as the elastic modulus is temperature-dependant, it is not necessarily appropriate to use identical yield strain criteria for all temperatures. As mentioned before, it is worth recalling that guidance available in the Eurocodes adopts a terminology through which the stress corresponding to deviation from linearity is referred to as $f_{s p, \theta}$; on the other hand, the term $f_{s y, \theta}$ is associated with the maximum level of stress in the bar at a temperature $\theta$, based on the assumption that strain hardening is negligible beyond a specific level of strain $\left(\varepsilon_{s y, \theta}\right)$.

Once the specimen and furnace were positioned within the test frame, the temperature was increased to the desired temperature. Heating was applied at a rate of $10^{\circ} \mathrm{C} / \mathrm{min}$ which has been shown to be realistic for structures exposed to fire [16]. The target temperature level was then maintained for 30 minutes to ensure a uniform temperature distribution throughout the specimen. The tensile loading was then applied gradually, through displacement control procedures at a rate of $4 \mathrm{~mm} / \mathrm{min}$, until final fracture occurred. A discussion of the main parameters evaluated in the tests is given below. 


\subsection{Initial Stiffness and Proportional Limit}

The experimental response curves obtained for the different reinforcing bars are shown in Figure 7 (a to e), presented in terms of stress against extension. The figures depict the behaviour for: (a) P6, (b) D6, (c) D8, (d) P10, and (e) D10. Particular emphasis was given to the smaller bars of 6 and $8 \mathrm{~mm}$ diameter, since the study was carried out as part of a wider examination dealing with composite slabs, as noted before. Accordingly, the number of steady-state temperatures considered was larger that that used for the $10 \mathrm{~mm}$ bars which were mainly used as a comparative add-on to the study.

The reduction in $E_{s, \theta}$ and $f_{s p, \theta}$ as evaluated from the test results are presented in Figures 8 and 9, respectively, for the different reinforcement types. Figure 8(a) presents the reduction in Young's Modulus $\left(E_{s, \theta}\right)$ with elevated temperature for each of the hotrolled bars (P6, P10 and D10), whereas the equivalent curves for the cold-worked reinforcement (D6 and D8) are illustrated in Figure 8(b). Similarly, the degradation in the proportional limit $\left(f_{s p, \theta}\right)$ is illustrated in Figures $9(\mathrm{a})$ and (b). In the curves presented in Figures 8 and 9, the reduction factors are normalised by their corresponding values at ambient conditions, and plotted against the temperature $(\theta)$. For comparison purposes, the plots also include the reduction factors suggested in the Eurocode 2 (EC2) [13] for hot-rolled and cold-worked bars.

The results presented in Figures 7, 8 and 9 provide direct information on the variation of initial stiffness and yield properties with temperature. Referring to the overall shape of the stress-strain response depicted in Figure 7, it is evident that the clear yield-plateau, demonstrated by the hot-rolled bars at ambient temperature, disappeared at temperature above $200^{\circ} \mathrm{C}$ and the behaviour became more continuous. Furthermore, in all cases, strain-hardening diminished from around $400-500^{\circ} \mathrm{C}$. In terms of $E_{s, \theta}$ and $f_{s p, \theta}$, Figures 8 and 9 indicate that both of these properties decreased gradually with temperature, and continued to reduce at a relatively constant rate at temperatures above $100-200^{\circ} \mathrm{C}$. It is noteworthy that the reduction factor on $E_{s, \theta}$ for $\mathrm{P} 10$ at $250^{\circ} \mathrm{C}$ appears to be inconsistent with the other results, which may be caused by an experimental measurement error. In general, the trends displayed in the experiments are broadly in agreement with those proposed in EC2, with the latter being on the conservative side in most cases. 


\subsection{Evaluation of Ultimate Strength}

Figure 10 illustrates the reduction in the ultimate stress reached in the tests $\left(f_{s u, \theta}\right)$ as a function of the steady-state temperature for: (a) hot-rolled and (b) cold-worked reinforcement. As before, the results have been normalised by their respective values at ambient temperature. For comparison, the plots also include the reduction factors suggested in Eurocode 2, corresponding to the maximum stress level which, importantly, is referred to as $f_{s y, \theta}$ in EC2. It is worth emphasising again that the Eurocodes assume that strain hardening is negligible at all temperatures and hence the maximum stress level is treated as an 'effective yield strength'. Although this may generally be a conservative assumption for design, the response curves depicted in Figure 7 show that strain hardening becomes insignificant only when temperatures above $400^{\circ} \mathrm{C}$ are reached. Accordingly, depending on the temperature level, the presence of strain hardening would result in an ultimate or maximum stress $\left(f_{s u, \theta}\right)$ that is higher than the effective yield point, $f_{s y, \theta}$. Characterisation of a representative effective yield strength at elevated temperature from the experimental results is therefore not possible without either: (i) defining a limiting strain criteria, which is difficult due to the variable $E_{s, \theta}$, or (ii) ignoring the presence of strain hardening characteristics as assumed in $\mathrm{EC} 2$.

Observation of the curves presented in Figure 10 indicates that all specimens behaved rather similarly in terms of the overall degradation in ultimate strength. The temperature at which this reduction was notable varied between around $250^{\circ} \mathrm{C}$ and $400^{\circ} \mathrm{C}$ but, following this point the rate of degradation was almost identical in all cases. It is worth noting that, similar to the $E_{s, \theta}$ and $f_{s p, \theta}$ properties discussed before, the difference in the reduction in ultimate strength for hot-rolled and cold-worked bars was not significant. At $700^{\circ} \mathrm{C}$, the maximum stress in all specimens was between $10-20 \%$ of the corresponding ambient value.

There is a general consensus that steel loses the cold-working effect at about $400^{\circ} \mathrm{C}$, and therefore the strength reduction of such material is expected to be greater than that for hot-rolled reinforcement at high temperatures [13]. However, this behaviour depends on the selected definition of reinforcement strength. Most assessments are conducted based on a design approach using an effective yield strength. In this study, $f_{s u, \theta}$ includes the post-yield hardening of the material which is considerably more significant for hot- 
rolled bars at ambient temperature. In fact, strain hardening is significantly less pronounced in cold-worked reinforcement, even at room temperature. Consequently, owing to the combination of: (i) each $f_{s u, \theta}$ term being normalised by its equivalent ambient value, and (ii) the progressive reduction of strain hardening as the temperature rises, the degradation of ultimate strength is exaggerated for the hot-rolled bars. In effect, the greater reduction in effective yield strength of the cold-formed bars is counterbalanced by the higher strain-hardening capacity in hot-rolled bars at ambient temperature. Consequently, both types display similar trends of ultimate strength when the normalised values are assessed.

\subsection{Reinforcement Ductility}

One of the main objectives of this experimental study was to gain an insight into the effect of elevated temperature on the ductility properties of steel reinforcement. Despite the dearth of specific information on this effect, it is clearly of direct relevance to the failure assessment of floor systems. With reference to Figure 1, Eurocode 2 crudely assumes that both $\varepsilon_{s t, \theta}$ and $\varepsilon_{s u, \theta}$ remain unchanged at any temperature and quantifies the terms as 0.15 and 0.2 respectively for Class $\mathrm{B}$ and $\mathrm{C}$ bars and 0.05 and 0.1 for Class $\mathrm{A}$ reinforcement.

In order to assess the ultimate strain $\left(\varepsilon_{s u, \theta}\right)$ of the reinforcing bars tested in this study, extension measurements were taken after cooling using the markings indicated on the specimens. In Figure 11, the strains are normalised to their equivalent values at ambient temperature and are depicted for the hot-rolled bars (Figure 11a) and cold-worked reinforcement (Figure 11b). As shown in the figures, the behaviour of both the hotrolled and cold-formed bars was comparable until around $500^{\circ} \mathrm{C}$, with the ultimate strain reaching around double the corresponding value at ambient in all cases. At higher temperatures, the enhancement in ultimate strain increased significantly for the coldworked bars, reaching values of between 7 to 9 times the ambient values at $700^{\circ} \mathrm{C}$. In contrast, the ultimate strains in hot-rolled reinforcement exhibited increases of only 2 to 3 times the ambient value at $700^{\circ} \mathrm{C}$. This disparity is attributed to the different manufacturing processes employed. Clearly, when the cold-working effect is alleviated at temperatures exceeding around $500^{\circ} \mathrm{C}$, the ductility increased significantly in comparison with the characteristically low values exhibited at ambient temperature for this type of reinforcement. 


\section{Transient Elevated Temperature Tests}

In this case, the specimens were subjected to an initial constant load at ambient temperature, which was then maintained as the temperature $(\theta)$ was progressively increased up to failure. Transient-state testing is clearly considered as the most realistic representation of an actual fire situation. However, transient tests are inherently more prohibitive in terms of time as well as interpretation of results. Loading and data acquisition procedures become significantly more demanding in comparison with steady-state tests. Accordingly, only a limited number of transient tests were carried out with the objective of examining the ability of the steady-state results to provide a reliable representation of the actual behaviour.

As in other tests, the temperature was increased at a rate of $10^{\circ} \mathrm{C} / \mathrm{min}$. The applied initial loads in each test, as well as the failure temperatures $\left(\theta_{f}\right)$, are presented in Table 2. The table also includes the predefined temperature range for each specimen $\left(\theta_{d}\right)$ within which failure was expected to occur based on the results of the steady-state tests. The initial applied load was selected using the information acquired from the steadystate tests discussed previously.

All specimens followed the same calibration procedure and hence, as an example, Test D8A is employed herein to describe the procedure. It is observed in Figure 7(c) that an applied stress of around $500 \mathrm{~N} / \mathrm{mm}^{2}$ ought to result in failure in the range of $400-500^{\circ} \mathrm{C}$. Accordingly, a constant tensile force of $25 \mathrm{kN}$, corresponding to a stress of $497 \mathrm{~N} / \mathrm{mm}^{2}$, was applied to the specimen at ambient conditions and maintained while the temperature was steadily increased. The reinforcement ruptured at a temperature of $482^{\circ} \mathrm{C}$ which is within the predicted range. Clearly, a more refined comparison would necessitate the availability of a larger number of tests at smaller increments. However, the results presented in Table 2 point to the general reliability of this approach.

The development of mechanical strain in each bar, as the temperature was increased, is depicted in Fig. 12. The effect of thermal expansion, both of the reinforcement and the strain-measuring device, has been removed from the data using the appropriate coefficients of thermal expansion as illustrated in Figure 2. As noted before, creep strain is not expected to have contributed significantly to the overall strain in the 
reinforcement as the test was of relatively short duration. The curves shown in the figure, which should be viewed in conjunction with the comparative values of $\theta_{d}$ and $\theta_{f}$ in Table 2, indicate that the behaviour obtained in the steady-state elevated temperature tests can be used to predict the response in transient conditions, provided that appropriate heating rates are applied.

Figure 12 also shows that the level of mechanical strain in the specimens was relatively low until shortly before the failure temperature was attained. As expected, this rapid increase in strain is related to yielding/necking of the bar followed by failure. The strain levels remained below the yield strain until shortly before the failure temperature was reached. As noted before, the failure temperature range was well predicted using the information from the steady-state tests.

\section{Assessment of Residual Properties}

In comparison with the reduction of stiffness and strength properties at elevated temperature, there is relatively limited information on the residual properties of reinforcement after cooling, particularly for cold-worked bars. Although general trends have been discussed [12], and some preliminary findings have been published [17], there appears to be a need for further quantitative examination of these aspects. Clearly, such information is vital for assessing the post-fire residual load-carrying capacity and ductility of a structural member or assemblage for the purposes of evacuation and rehabilitation.

In light of the above, the residual properties of both hot-rolled (P6) and cold-worked (D6 \& D8) reinforcement specimens was examined experimentally. In each case, the specimen was heated to a specific temperature level which was maintained for at least 30 mins, before being cooled slowly to room temperature and then loaded up to failure. As with the previously-discussed ambient tensile tests, an extensometer was employed to measure the extension over a $100 \mathrm{~mm}$ gauge length, until failure was reached by reinforcement fracture..

The residual stress-strain response after each thermal cycle is illustrated in Figure 13 for (a) P6, (b) D6 and (c) D8. In addition, Figure 14 depicts the effect of temperature on the post-cooling residual properties, represented in terms of the normalised reduction or enhancement factor for each of (a) $E_{s, r}$; (b) $f_{s y, r}$; (c) $f_{s u, r}$; and (d) $\varepsilon_{s u, r}$; each term has been 
normalised by its corresponding value at normal ambient conditions. As shown in Figure 13(a), P6 bars were hot-rolled and therefore a clear yield point is evident in the response. On the other hand, the $0.2 \%$ proof stress was used for D6 and D8 due to the absence of a well-defined yield point in cold-worked reinforcement although, as expected, this changes following exposure to relatively high temperature levels as discussed below.

Both Figure 13(a) and Figure 14(a-d) indicate that the hot-rolled reinforcement P6 tended to recover its original stiffness and strength within the range of temperatures considered in this study. In terms of ductility, the residual ultimate strain remained largely unaffected until the temperature exceeded $400^{\circ} \mathrm{C}$; at $600^{\circ} \mathrm{C}$, the enhancement in $\varepsilon_{s u, \theta}$ compared to the ambient value was around $50 \%$. It should be noted that, unlike in the steady-state tests (e.g. Figure 7a), the characteristic yield point was present when the hot-rolled bars were tested after cooling from temperatures exceeding $300^{\circ} \mathrm{C}$ as shown in Figure 13a. This observation is in agreement with recent investigations [18] which suggested the yield plateau exists up to temperatures reaching $800^{\circ} \mathrm{C}$. However, this is different from earlier discussions [12] suggesting that the yield plateau is not recovered after cooling, although this conclusion does not appear to have been validated by experimental evidence related specifically to the residual response.

The cold-worked reinforcement specimens, D6 and D8, displayed similar behavioural trends to each other as shown in Figures 13 and 14. Up to temperatures reaching $400^{\circ} \mathrm{C}$, there was no noticeable change in the stiffness, strength or ductility of these specimens. Beyond this, when a temperature of $600^{\circ} \mathrm{C}$ was applied, whilst the stiffness was retained, there was a slight reduction in yield and ultimate strength which was within about 10\%-15\%. In terms of ductility, both D6 and D8 exhibited an ultimate strain enhancement of around $150 \%$ at $600^{\circ} \mathrm{C}$, with D6 increasing from around 0.04 to 0.1 whereas D8 changed from 0.05 to 0.13 . The significant change in residual properties of the cold-worked bars following exposure to temperatures exceeding $400^{\circ} \mathrm{C}$ is also evident in Figures $13 \mathrm{~b}$ and 13c. The notable reduction in strength and associated significant increase in ductility for $600^{\circ} \mathrm{C}$, coupled with the presence of a conventional yield plateau, demonstrates the loss of the cold-working effect when the bars are subjected to this level of temperature. 


\section{Concluding Remarks}

This paper presented the results and observations from a series of ambient and elevated temperature tests on hot-rolled and cold-worked reinforcement. The tests focused on assessing the behaviour of plain and deformed bars of relatively small diameters that may typically be employed in composite slabs. Consideration was given to temperature levels that may realistically be reached by the reinforcement within the cross-section of composite slabs in a fire situation. The material response was investigated under both steady-state and transient elevated temperature conditions. In addition to examination of the stress-strain behaviour, emphasis was also given to the influence of temperature on ductility in terms of ultimate stress-induced mechanical strain at fracture. Moreover, the residual properties of the reinforcement after cooling were examined.

The expected difference in the shape of the stress-strain response of hot-rolled and coldworked reinforcement was evident in the steady-state tests. In terms of reduction in stiffness and strength with temperature, it was shown that the test results were in broad agreement with the factors proposed in EC2 in most cases. Nevertheless, some caution is warranted in the interpretation of ultimate strength in EC2 due to the disregard for strain hardening at all temperature levels. On the other hand, the approach adopted by EC2, in which the ultimate mechanical strain is assumed to be unaffected by temperature, was shown by the test results to be overly conservative. For hot-rolled bars, the experimental ultimate strains increased by a factor of over two at $600^{\circ} \mathrm{C}$. On the other hand, the enhancement of ultimate strains in cold-worked bars was in excess of 3 times at $600^{\circ} \mathrm{C}$ and increased more rapidly at higher temperatures. In other words, the significant difference in ductility at ambient conditions between hot-rolled and coldworked bars is reduced at high temperatures as the cold-working effect diminishes.

The experimental results also showed that the post-cooling residual properties of both hot-rolled and cold-worked reinforcement bars remain largely unchanged up to $400^{\circ} \mathrm{C}$. At higher temperature levels, there is a reduction in strength reaching $10-15 \%$ in the case of cold-worked bars for $600^{\circ} \mathrm{C}$. More importantly, the enhancement in the residual ultimate mechanical strain at $600^{\circ} \mathrm{C}$ was shown to be about $50 \%$ in hot-rolled specimens and about $150 \%$ in the case of cold-worked bars. Clearly, the findings related to ultimate mechanical strain at elevated temperature and after cooling, are critical for the 
reliable assessment of the performance of structural members in fire, as well as for postfire rehabilitation considerations.

\section{Acknowledgements}

The support provided by the Engineering and Physical Sciences Research Council (EPSRC) in the UK for the work described in this paper is gratefully acknowledged. The authors would also like to thank the technical staff of the structures laboratories at Imperial College London, particularly Mr. Trevor Stickland, for their assistance with the experimental work.

\section{References}

[1] Kirby B.R. (1997). "British steel technical European fire test programme - Design, construction and results." Fire, static and dynamic tests of building structures, G. Armer and T. O’Neill, eds., Spon, London

[2] O' Connor, M. A. and Martin, D. M. (1998). "Behaviour of multi-storey steel framed buildings subjected to fire attack", Journal of Constructional Steel Research 46(1-3). Paper No: 169.

[3] Wang, Y.C., Lennon, T., and Moore, D.B (1995). "The behaviour of steel frames subject to fire", Journal of Constructional Steel Research, Vol. 35, pp. 291-322.

[4] Huang, Z., Burgess, I. W. and Plank, R. J. (1999). "Nonlinear analysis of reinforced concrete slabs subjected to fire", American Concrete Institute Structural Journal 96(1), pp. 127-135.

[5] Elghazouli, A. Y. and Izzuddin, B. A. (2001). "Analytical assessment of the structural performance of composite floors subject to compartment fires", Fire Safety Journal, 36, pp. 769-793.

[6] Gillie, M., Usmani, A.S., and Rotter, J.M. (2001). "A structural analysis of the first Cardington test", Journal of Constructional Steel Research, Vol. 57, pp. 581-601.

[7] Izzuddin, B. A. and Elghazouli, A. Y. (2004). "Failure of lightly reinforced concrete members under fire. I: Analytical modelling”, Journal of Structural Engineering, 130(1):3-17 
[8] Elghazouli, A. Y. and Izzuddin, B. A. (2004). "Failure of lightly reinforced concrete members under fire. II: Parametric studies and design considerations." Journal of Structural Engineering, 130(1):18-31

[9] Omer, E., Izzuddin, B.A. and Elghazouli A.Y. (2006). "Failure assessment of simply supported floor slabs under elevated temperature." Structural Engineering International, 16(2):148-155

[10]Omer, E., Izzuddin, B.A., Elghazouli, A.Y. (2005), "Simplified method for failure assessment of composite slabs subject to fire.” IABSE Symposium on Structures and Extreme Events, Lisbon, Portugal, IABSE. Pages: 278-279

[11]Buchanan, A.H. (2001). "Structural Design for Fire Safety.” Wiley, UK

[12]Anderberg Y. (1978). "Analytical fire engineering design of reinforced concrete structures based o real fire conditions." Proceedings of the FIP Congress, London. Part 1: 112-121.

[13]Eurocode 2 (2004). "Design of concrete structures: Part 1.2: General rules Structural fire design" European Committee for Standardization, Brussels. BS EN 1992-1-2.

[14]Twilt L. (1988). "Strength and deformation properties of steel at elevated temperatures: Some practical implications." Fire Safety Journal, Vol. 13, pp 9-15.

[15] EN ISO 15630-1 (2002). "Steel for the reinforcement and prestressing of concrete - Test methods - Part 1: Reinforcing bars, wire rod and wire." International Standards Organisation, Geneva, Switzerland.

[16] Wang Y.C. (2002). "Steel and composite structures - Behaviour and design for fire safety." Spon, London.

[17] CEB-FIP (2008). "Fire design of concrete structures - structural behaviour and assessment: State-of-the-Art Report." International Federation for Structural Concrete (fib), Lausanne, Switzerland.

[18] Topçu I.B. and Karakurt C. (2008). "Properties of Reinforced Concrete Steel Rebars Exposed to High Temperatures." Materials Science, Vol. 2008, Article ID 814137. 
Ambient steel reinforcement properties

\begin{tabular}{|c|c|c|c|}
\hline & $\boldsymbol{f}_{\boldsymbol{s y}, \mathbf{2 0}{ }^{\circ} \boldsymbol{C}}$ & $\boldsymbol{f}_{\mathbf{s u}, \mathbf{2 0}{ }^{\circ} \boldsymbol{C}}$ & $\boldsymbol{\varepsilon}_{\boldsymbol{s u}, \mathbf{2 0}{ }^{\circ} \mathbf{C}}$ \\
\hline P6 & 251 & 328 & 0.20 \\
\hline D6 & 551 & 592 & 0.04 \\
\hline D8 & 551 & 624 & 0.05 \\
\hline P10 & 469 & 550 & 0.15 \\
\hline D10 & 581 & 679 & 0.14 \\
\hline
\end{tabular}

Table 1: Transient test results

\begin{tabular}{|c|c|c|c|c|}
\hline BAR TYPE: PG & $\begin{array}{l}\text { Applied load } \\
(\mathrm{kN})\end{array}$ & $\begin{array}{c}\text { Equivalent Stress } \\
\left(\mathrm{N} / \mathrm{mm}^{2}\right)\end{array}$ & $\theta_{d}\left({ }^{\circ} \mathrm{C}\right)$ & $\theta_{f} \quad\left({ }^{\circ} \mathrm{C}\right)$ \\
\hline Specimen A & 6 & 203 & $400-500$ & 476 \\
\hline Specimen B & 2 & 81 & $600-700$ & 637 \\
\hline BAR TYPE: D6 & $\begin{array}{l}\text { Applied load } \\
(\mathrm{kN})\end{array}$ & $\begin{array}{c}\text { Equivalent Stress } \\
\left(\mathrm{N} / \mathrm{mm}^{2}\right)\end{array}$ & $\theta_{d}\left({ }^{\circ} \mathrm{C}\right)$ & $\theta_{f} \quad\left({ }^{\circ} \mathrm{C}\right)$ \\
\hline Specimen A & 13 & 451 & $400-500$ & 451 \\
\hline Specimen B & 5 & 177 & $600-700$ & 666 \\
\hline BAR TYPE: $D 8$ & $\begin{array}{l}\text { Applied load } \\
(\mathrm{kN})\end{array}$ & $\begin{array}{c}\text { Equivalent Stress } \\
\left(\mathrm{N} / \mathrm{mm}^{2}\right)\end{array}$ & $\theta_{d}\left({ }^{\circ} \mathrm{C}\right)$ & $\theta_{f} \quad\left({ }^{\circ} \mathrm{C}\right)$ \\
\hline Specimen A & 25 & 497 & $400-500$ & 487 \\
\hline Specimen B & 9 & 175 & $600-700$ & 648 \\
\hline BAR TYPE: P10 & $\begin{array}{c}\text { Applied load } \\
(\mathrm{kN})\end{array}$ & $\begin{array}{c}\text { Equivalent Stress } \\
\left(\mathrm{N} / \mathrm{mm}^{2}\right)\end{array}$ & $\theta_{d}\left({ }^{\circ} \mathrm{C}\right)$ & $\theta_{f} \quad\left({ }^{\circ} \mathrm{C}\right)$ \\
\hline Specimen A & 20 & 255 & $500-600$ & 550 \\
\hline BAR TYPE: D10 & $\begin{array}{l}\text { Applied load } \\
(\mathrm{kN})\end{array}$ & $\begin{array}{c}\text { Equivalent Stress } \\
\left(\mathrm{N} / \mathrm{mm}^{2}\right)\end{array}$ & $\theta_{d}\left({ }^{\circ} \mathrm{C}\right)$ & $\theta_{f} \quad\left({ }^{\circ} \mathrm{C}\right)$ \\
\hline Specimen A & 25 & 318 & $500-600$ & 562 \\
\hline
\end{tabular}




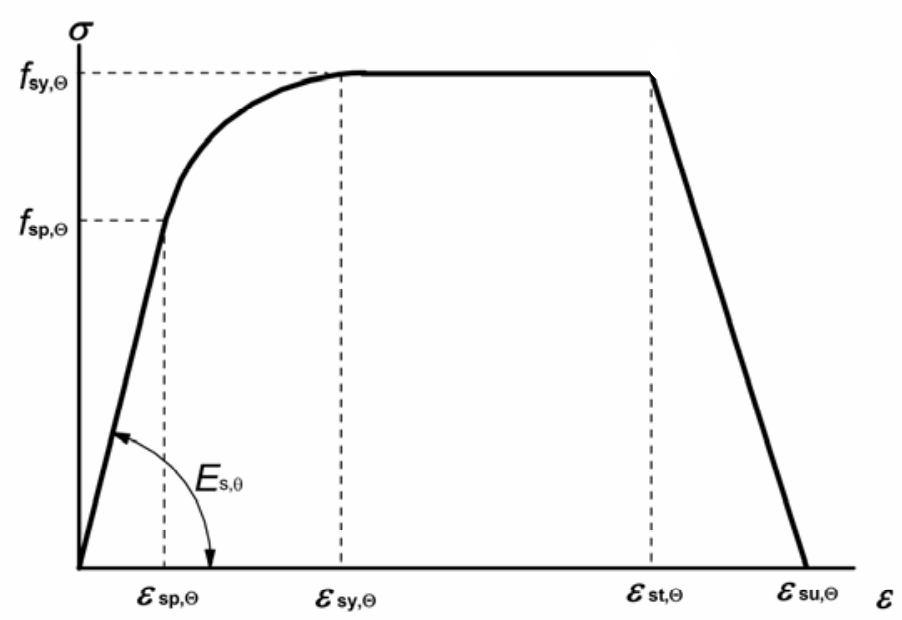

Figure 1 Stress-strain relationship for reinforcing bars at elevated temperatures [13]

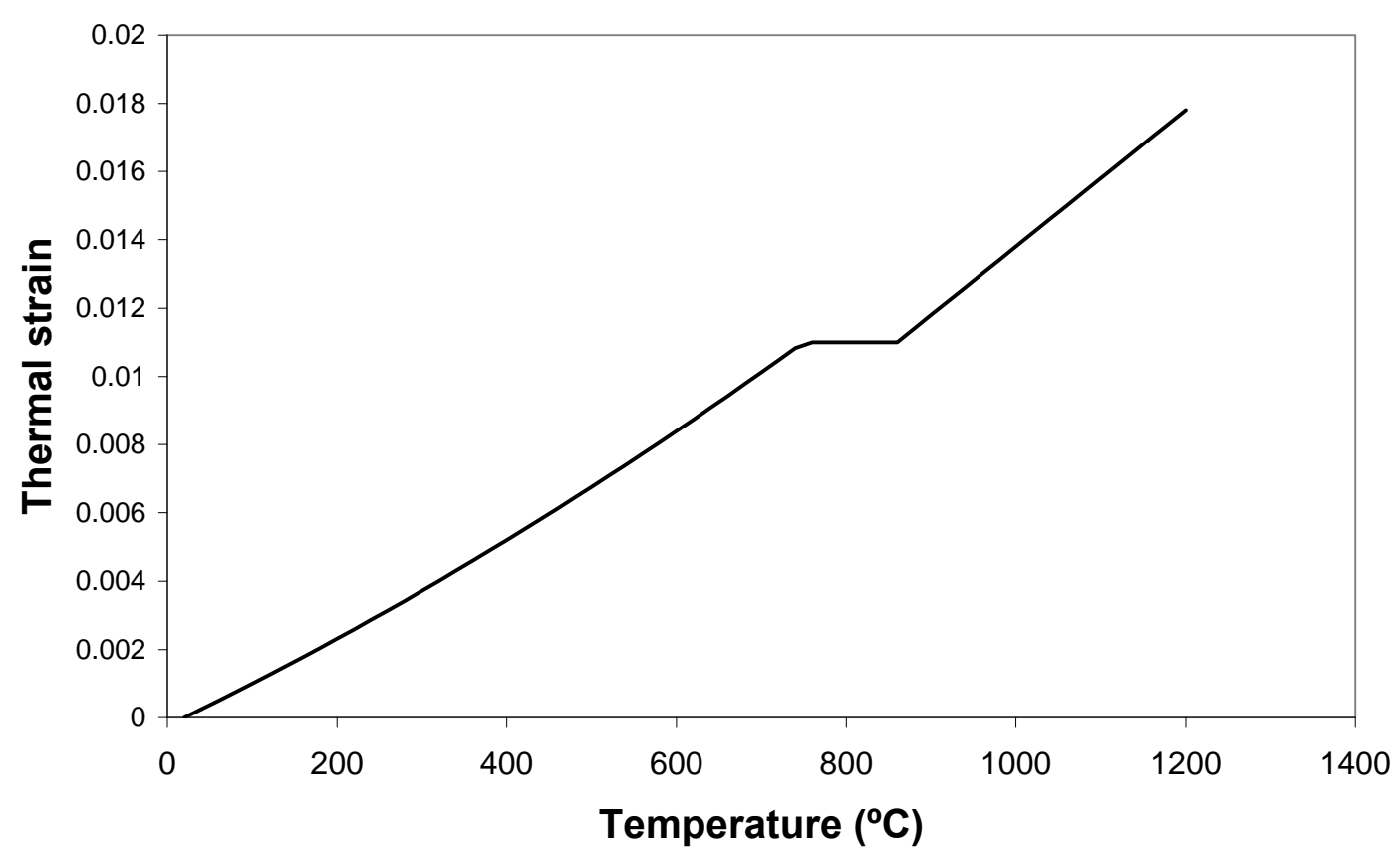

Figure 2 Thermal elongation of structural and reinforcing steel according to EC2 [13] 


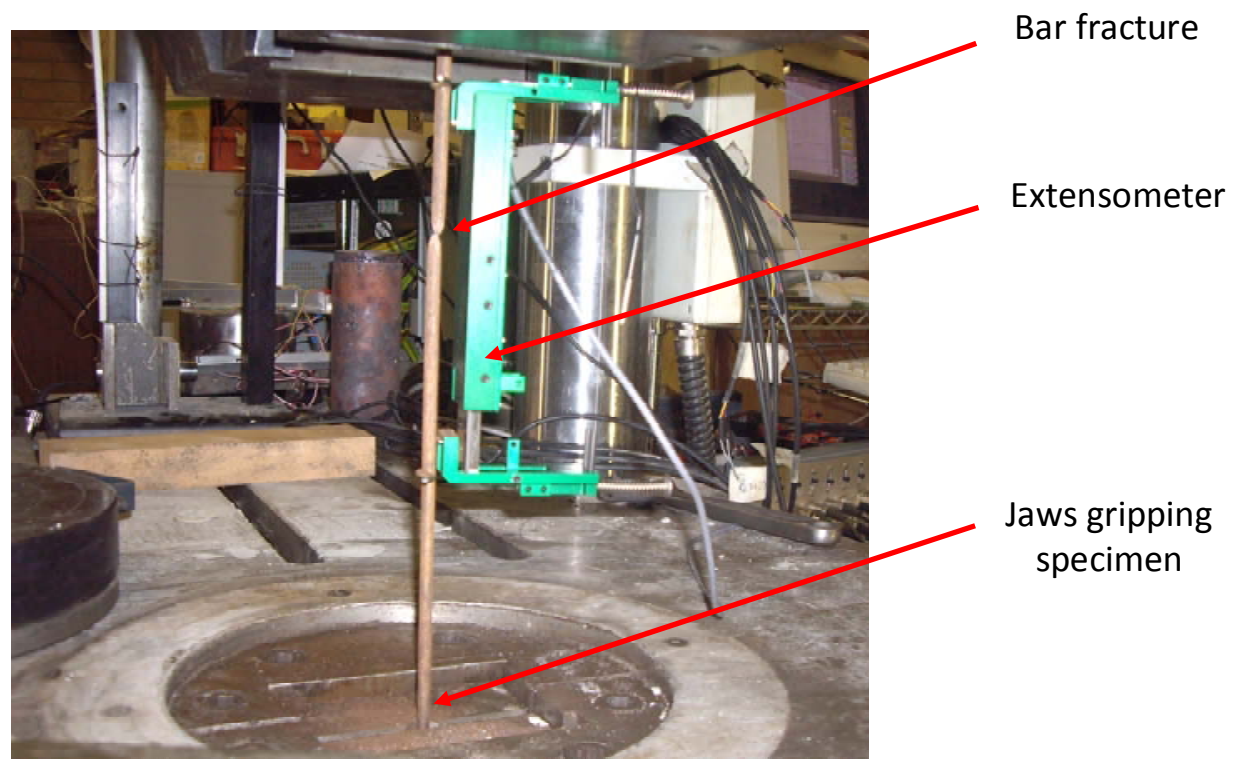

Figure 3 Image of instrumentation employed to measure extension

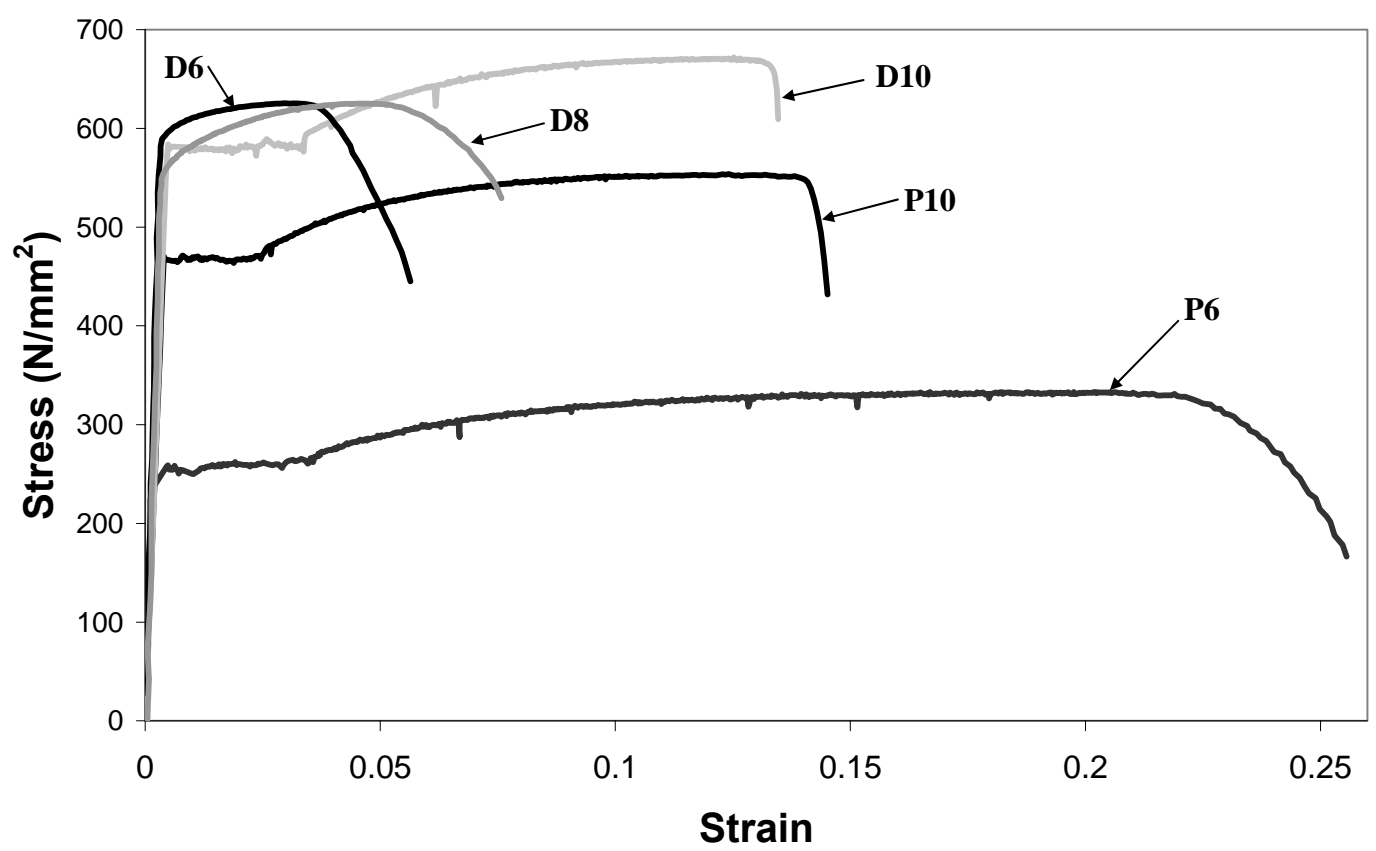

Figure 4 Typical stress-strain relationships at ambient temperature 


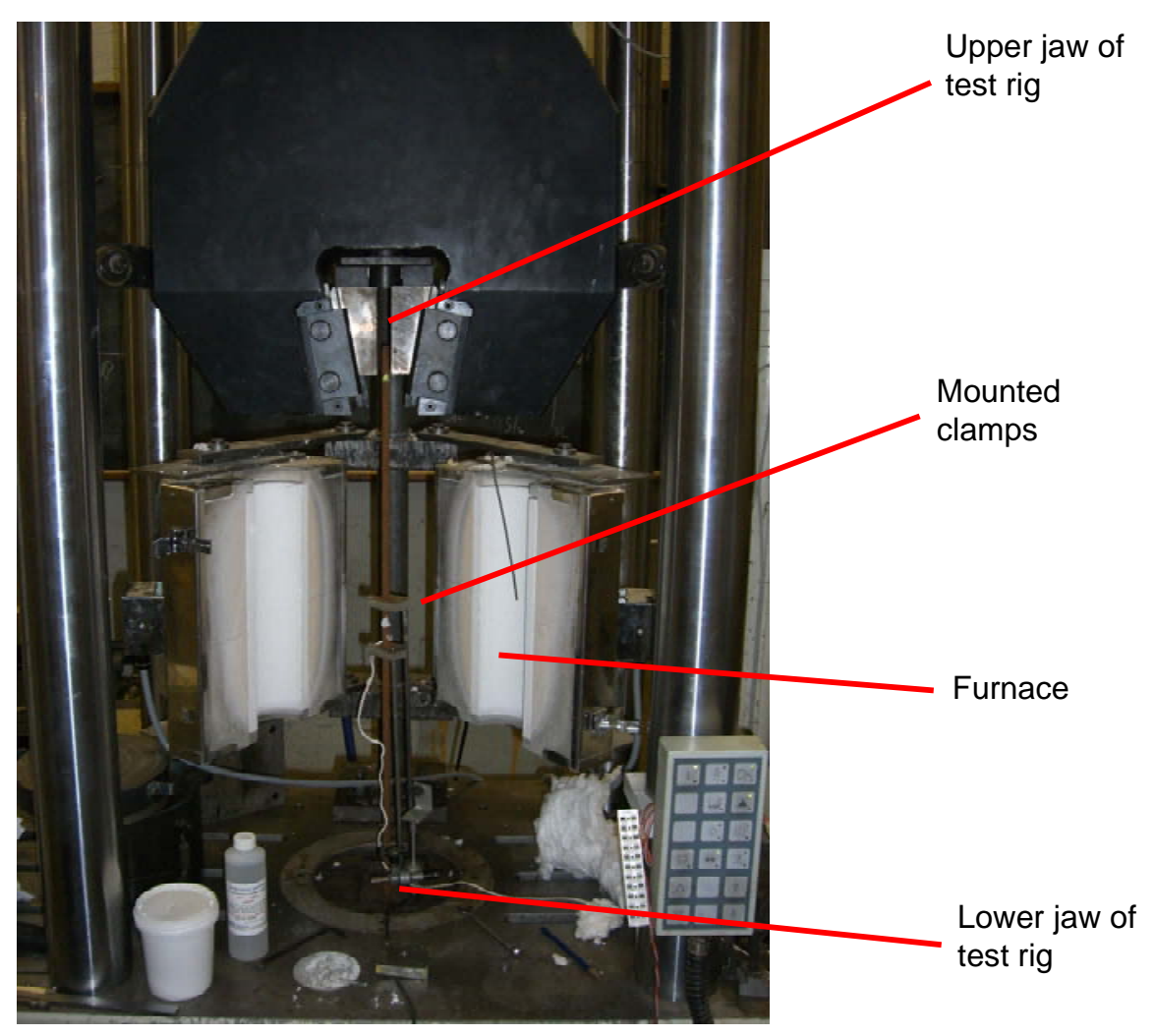

Figure 5 Elevated temperature testing arrangement 


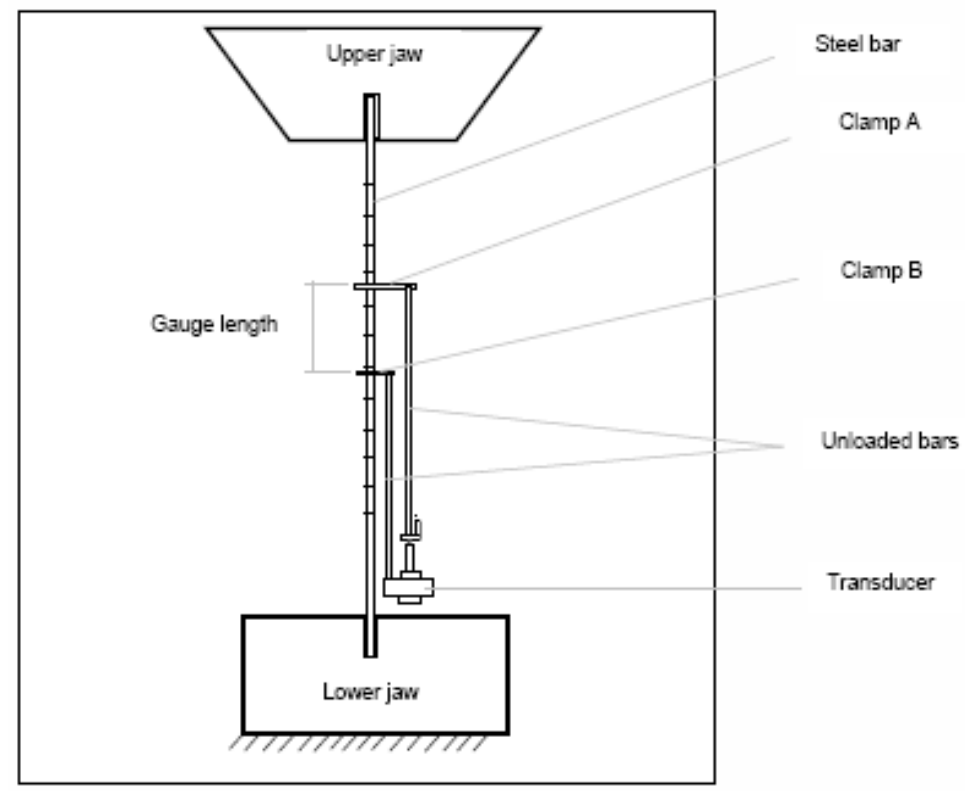

Figure 6 Arrangement for measuring bar extension 


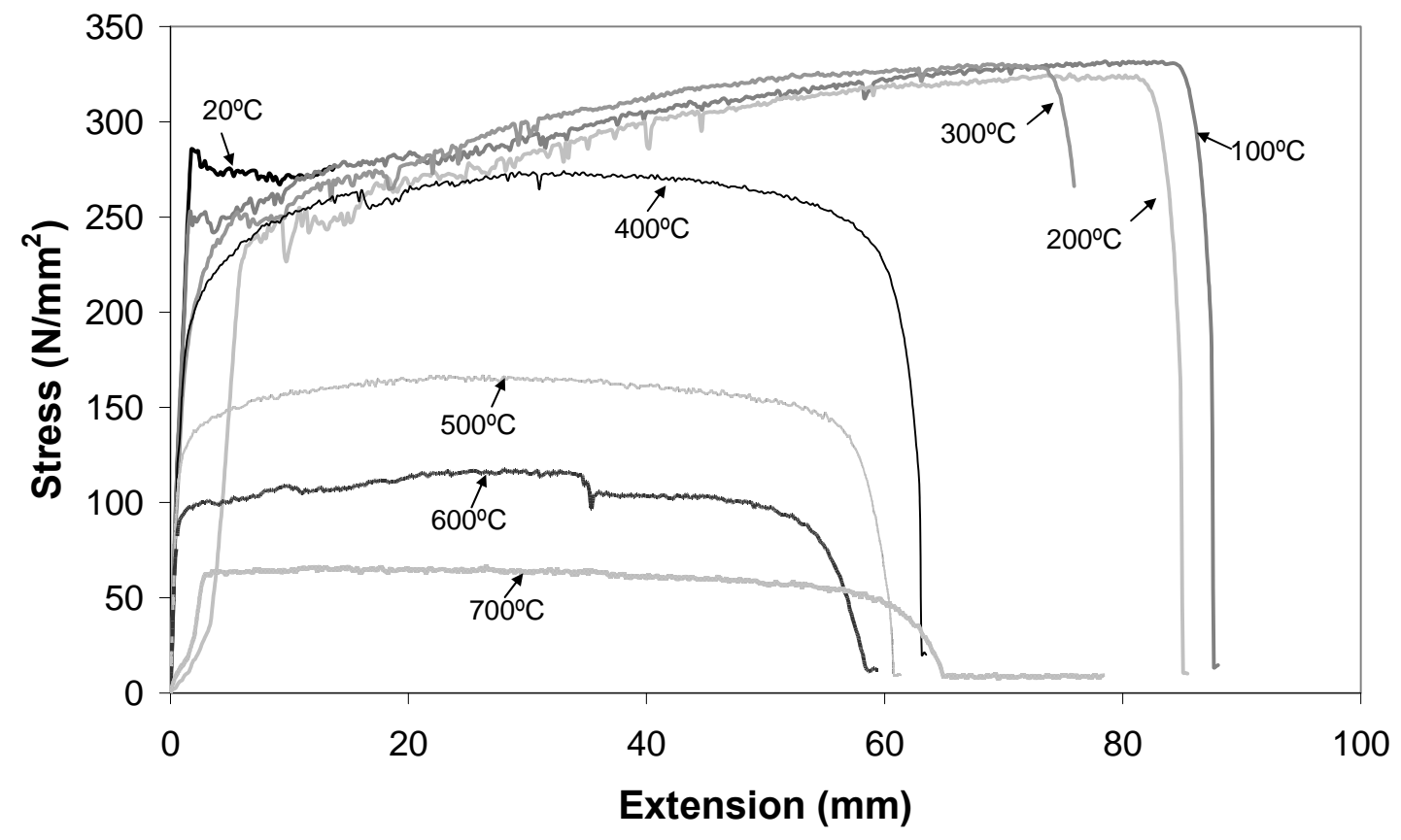

(a) P6

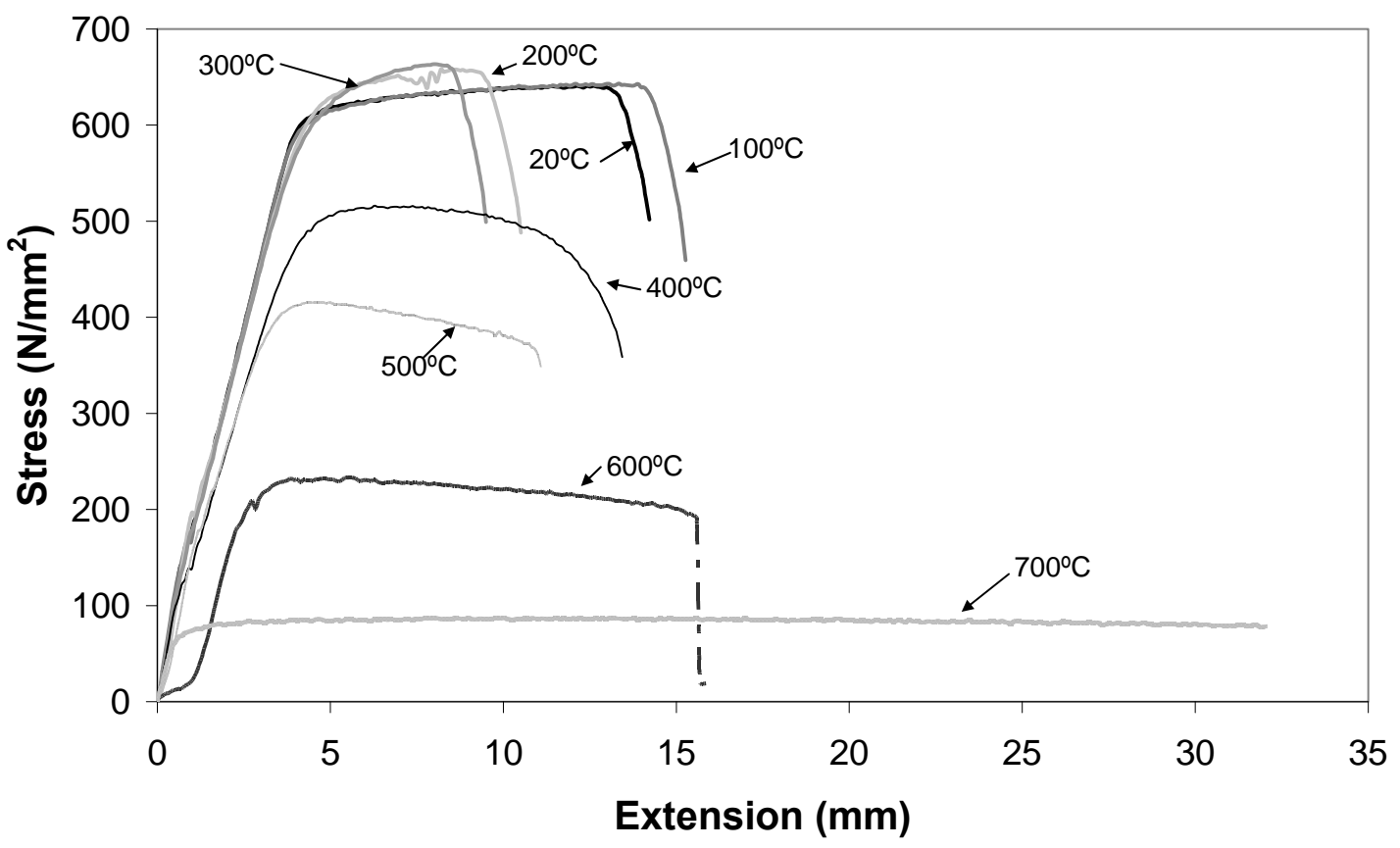

(b) $\mathrm{D} 6$ 


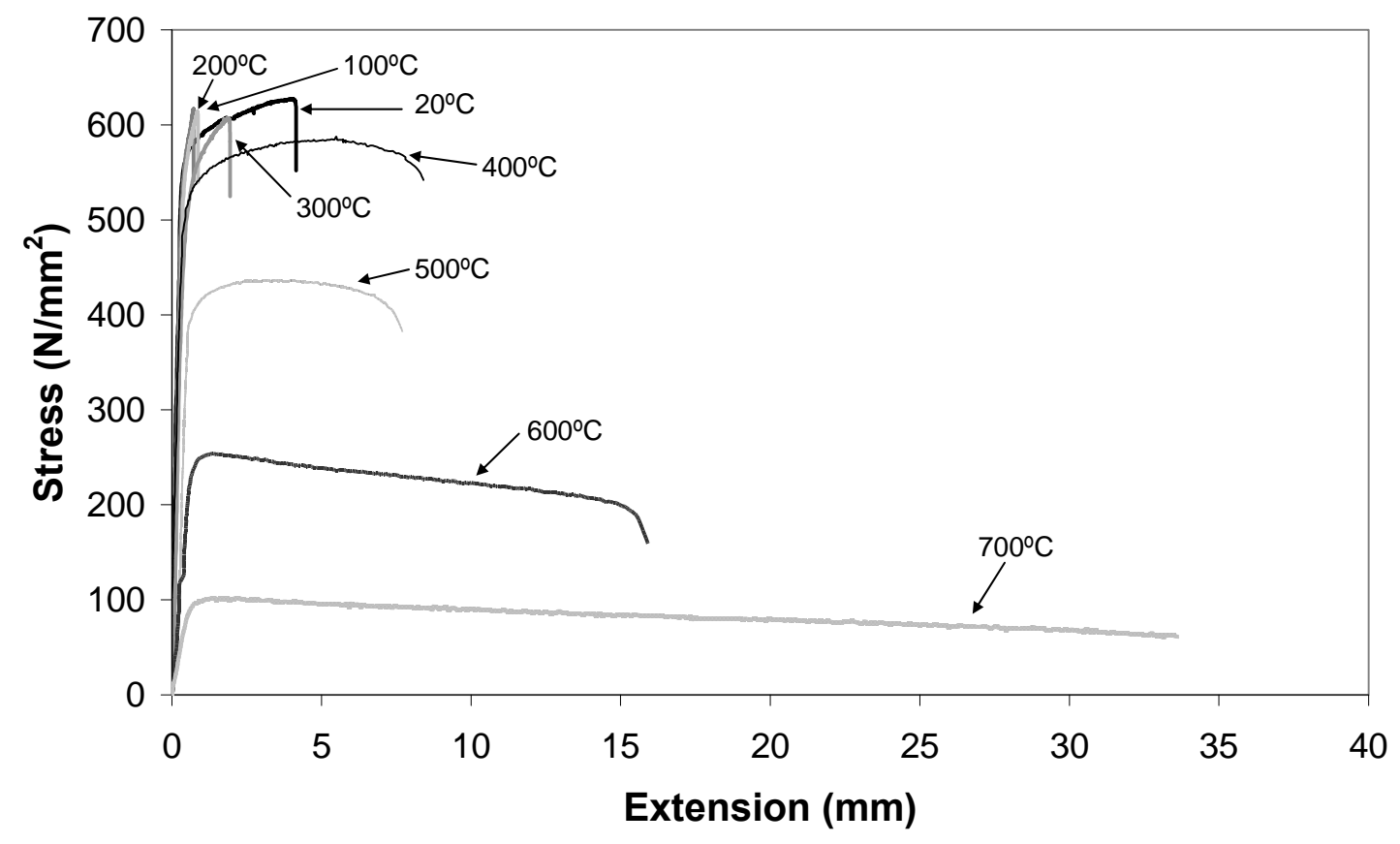

(c) $\mathrm{D} 8$

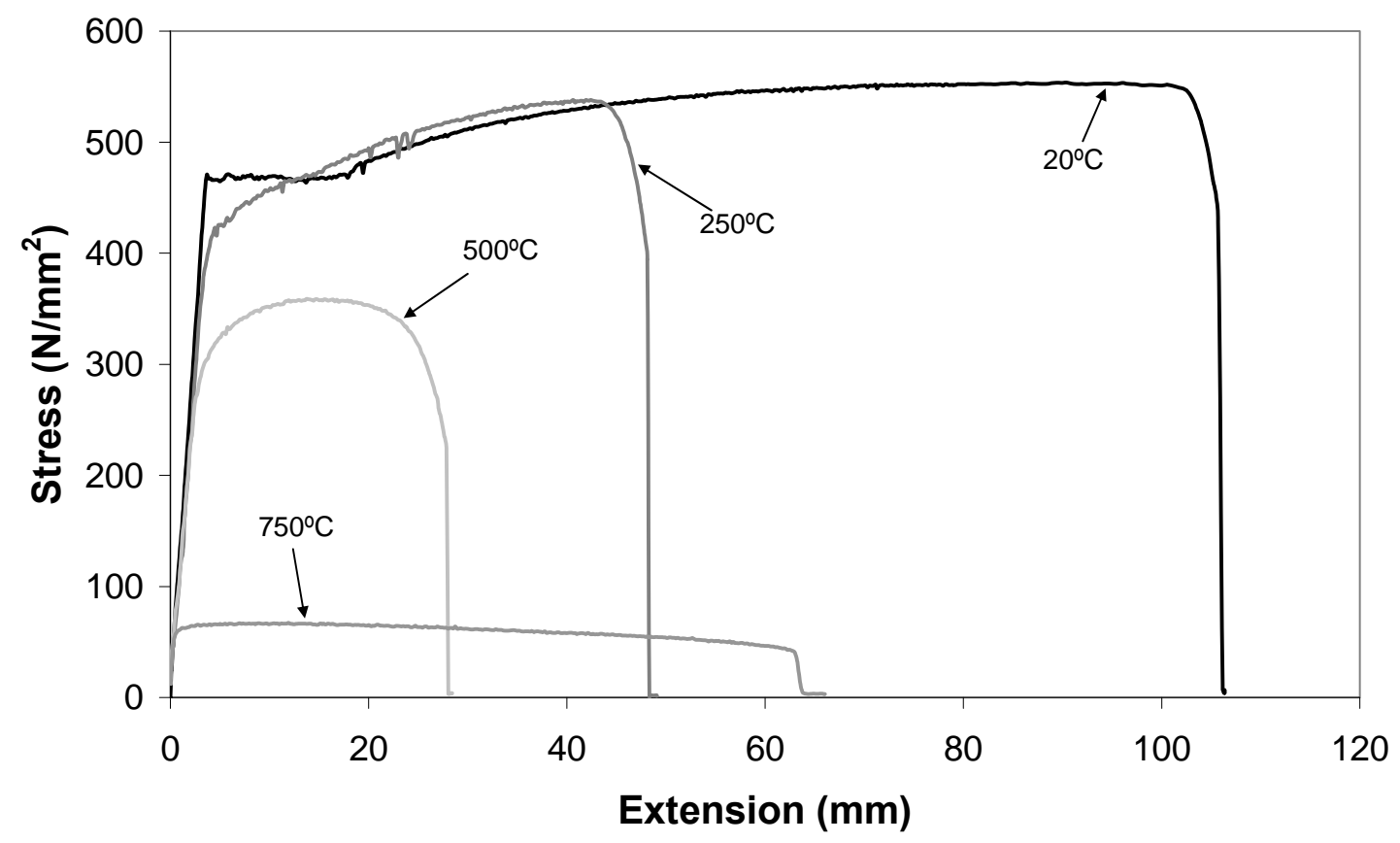

(d) P10 


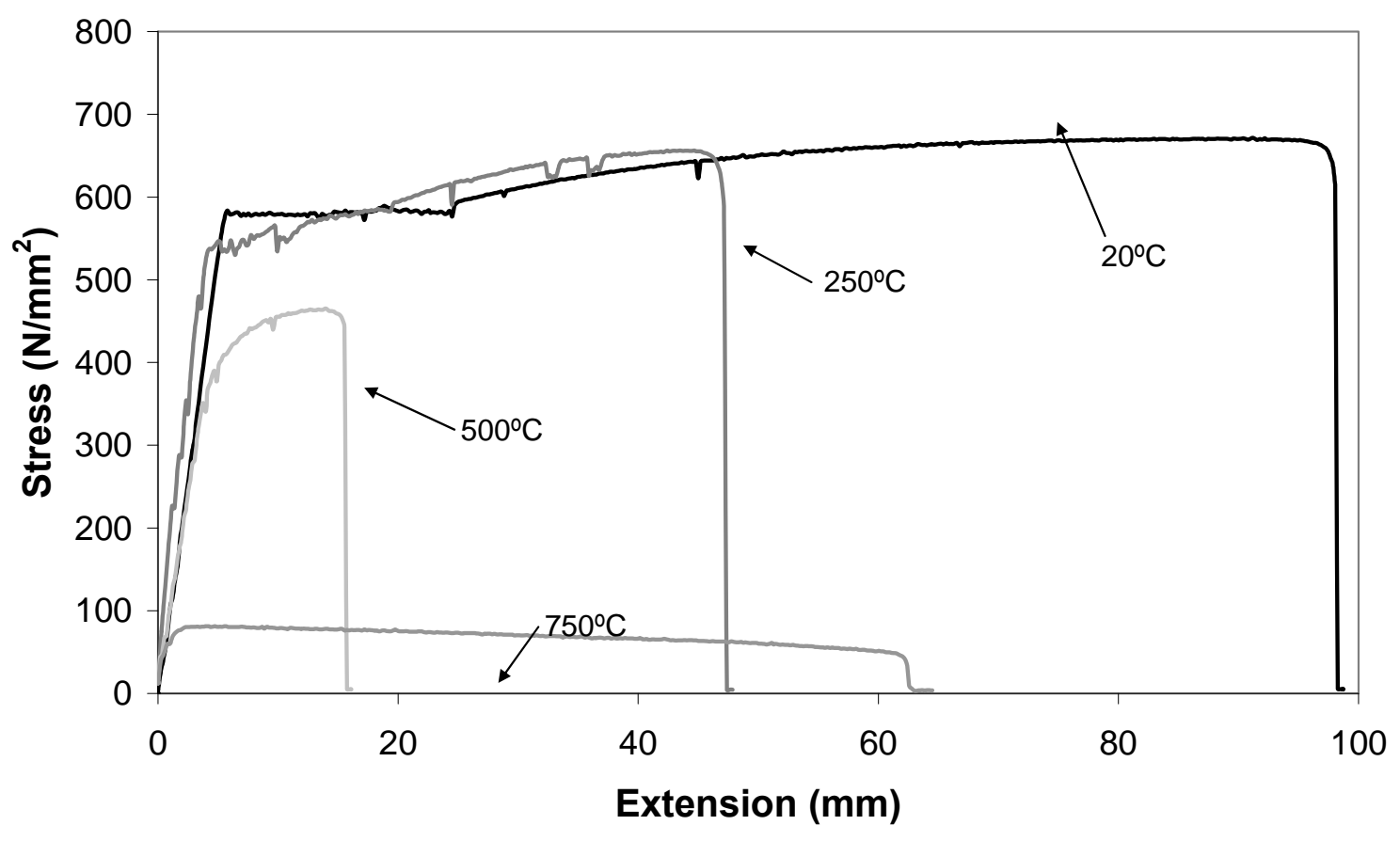

(e) D10

Figure 7 Stress versus extension response for (a) P6; (b) D6; (c) D8; (d) P10; and (e) D10 at various temperatures 


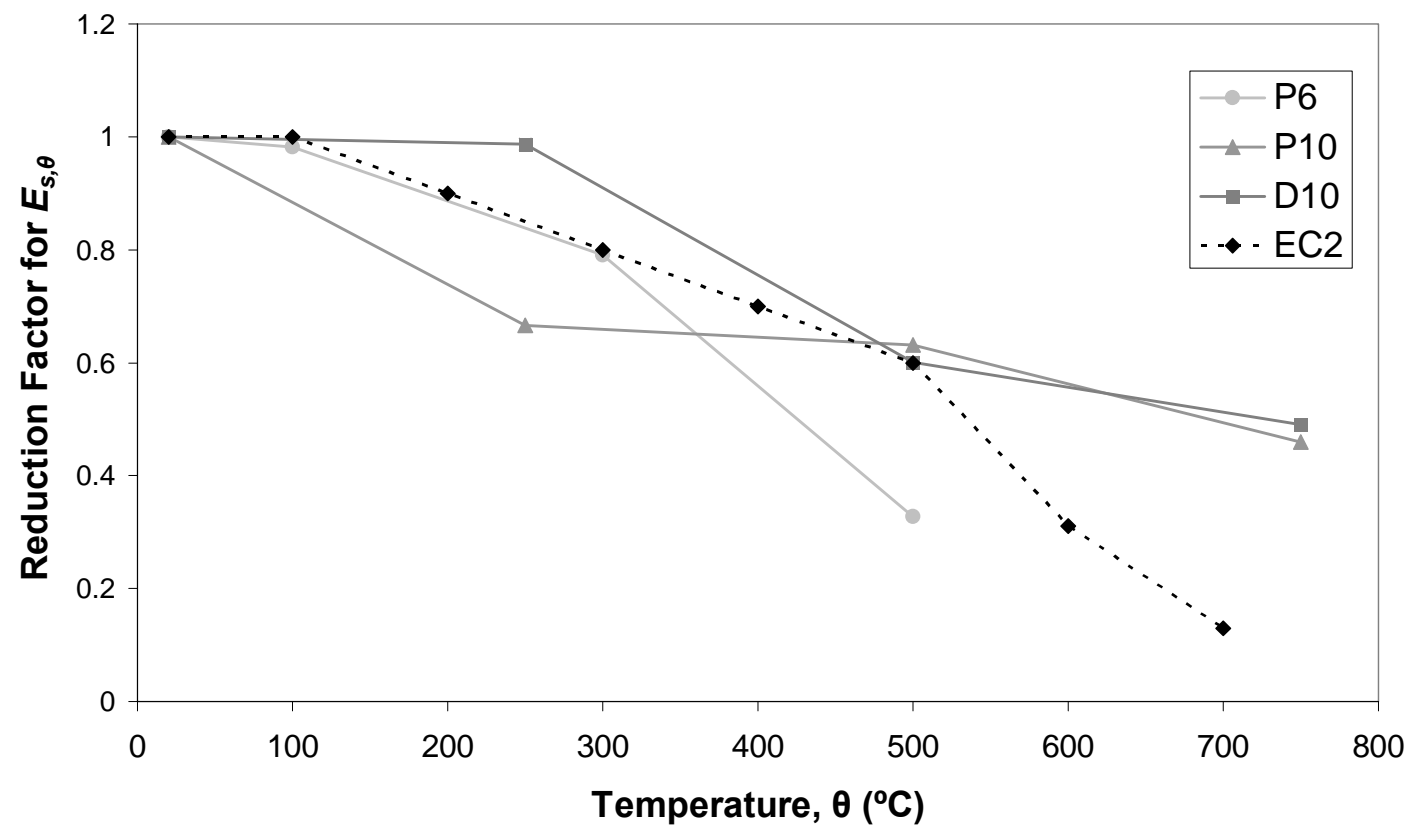

(a)

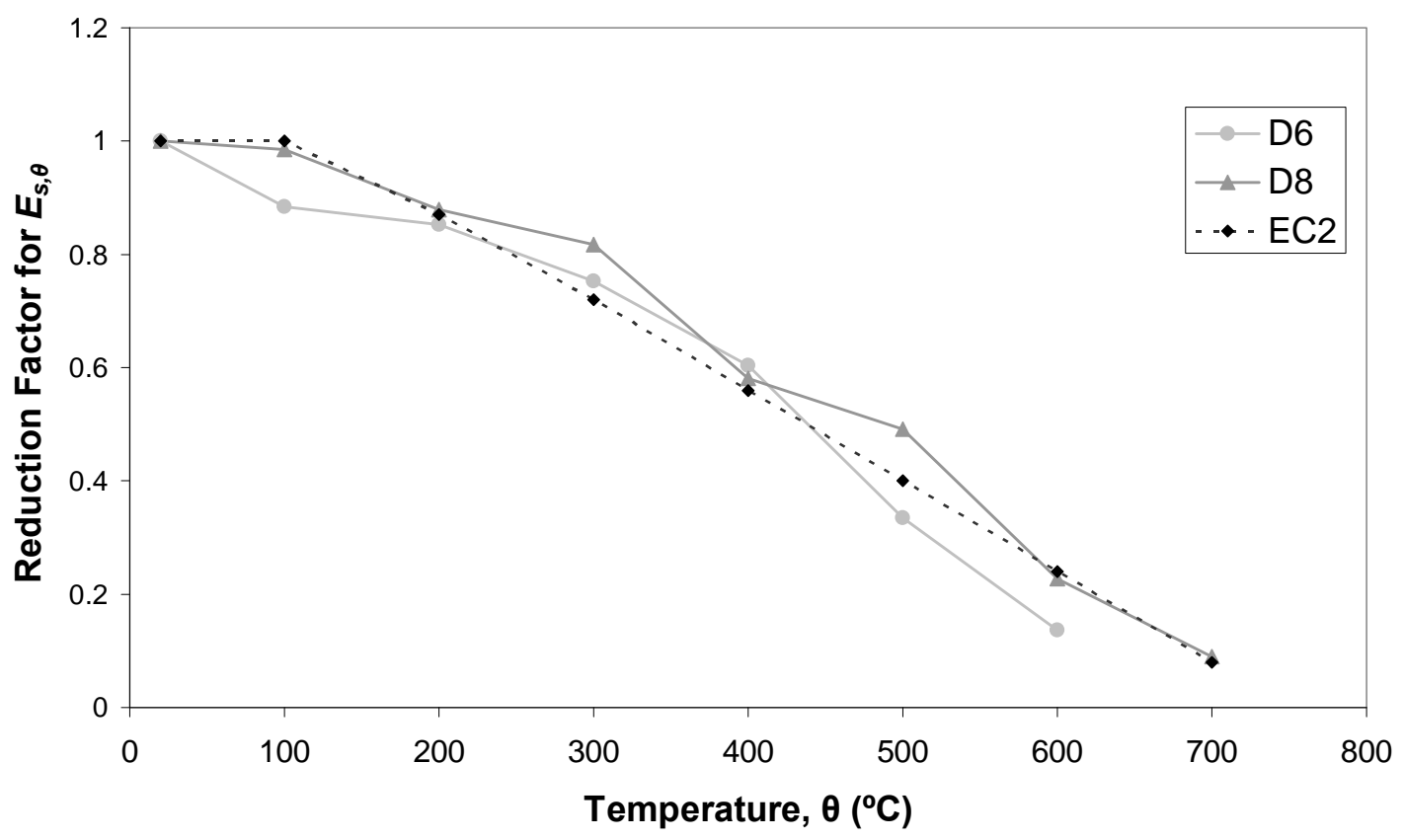

(b)

Figure 8 Effect of elevated temperature on $E_{S, \theta}$ for (a) hot-rolled specimens and (b) cold-worked specimens 


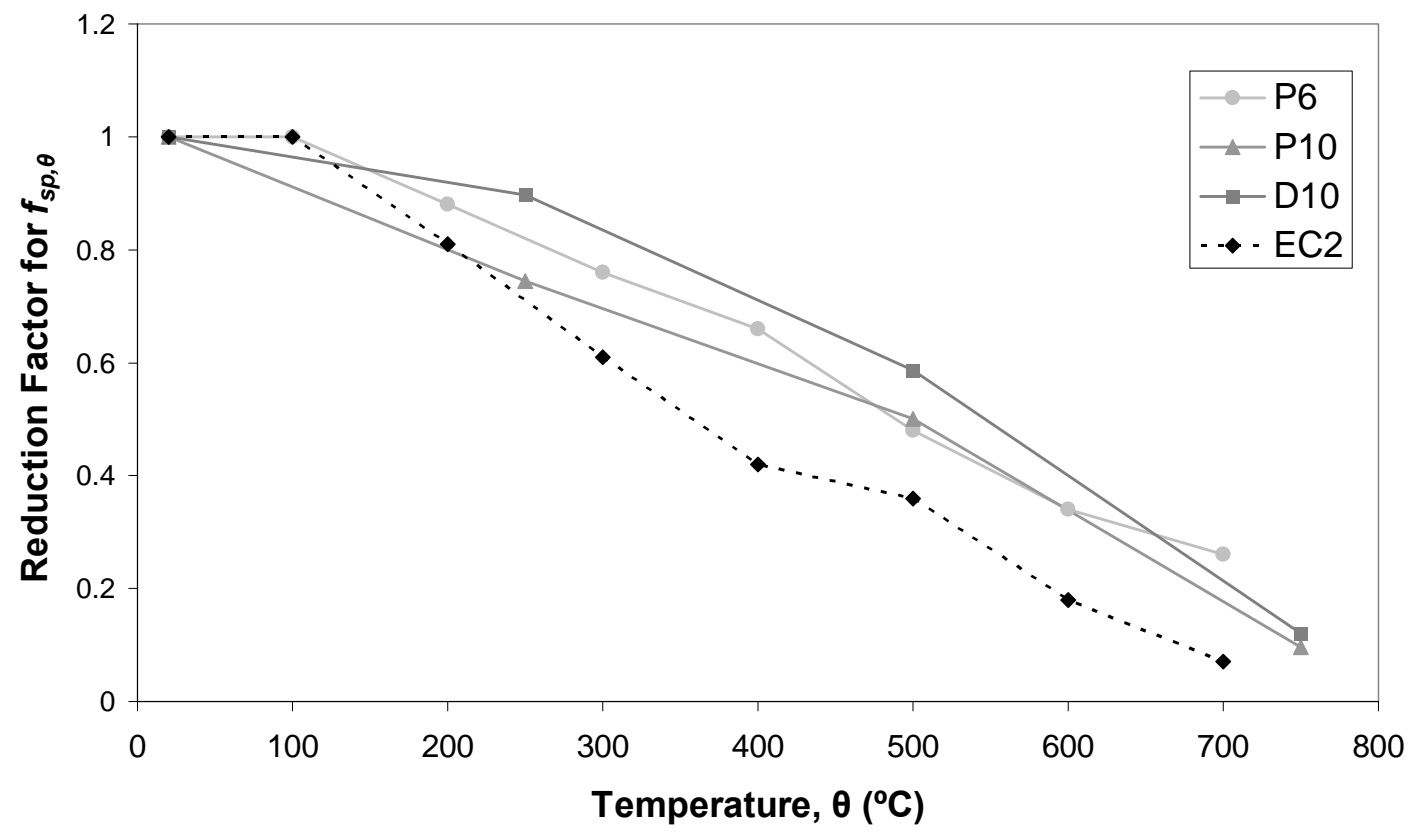

(a)

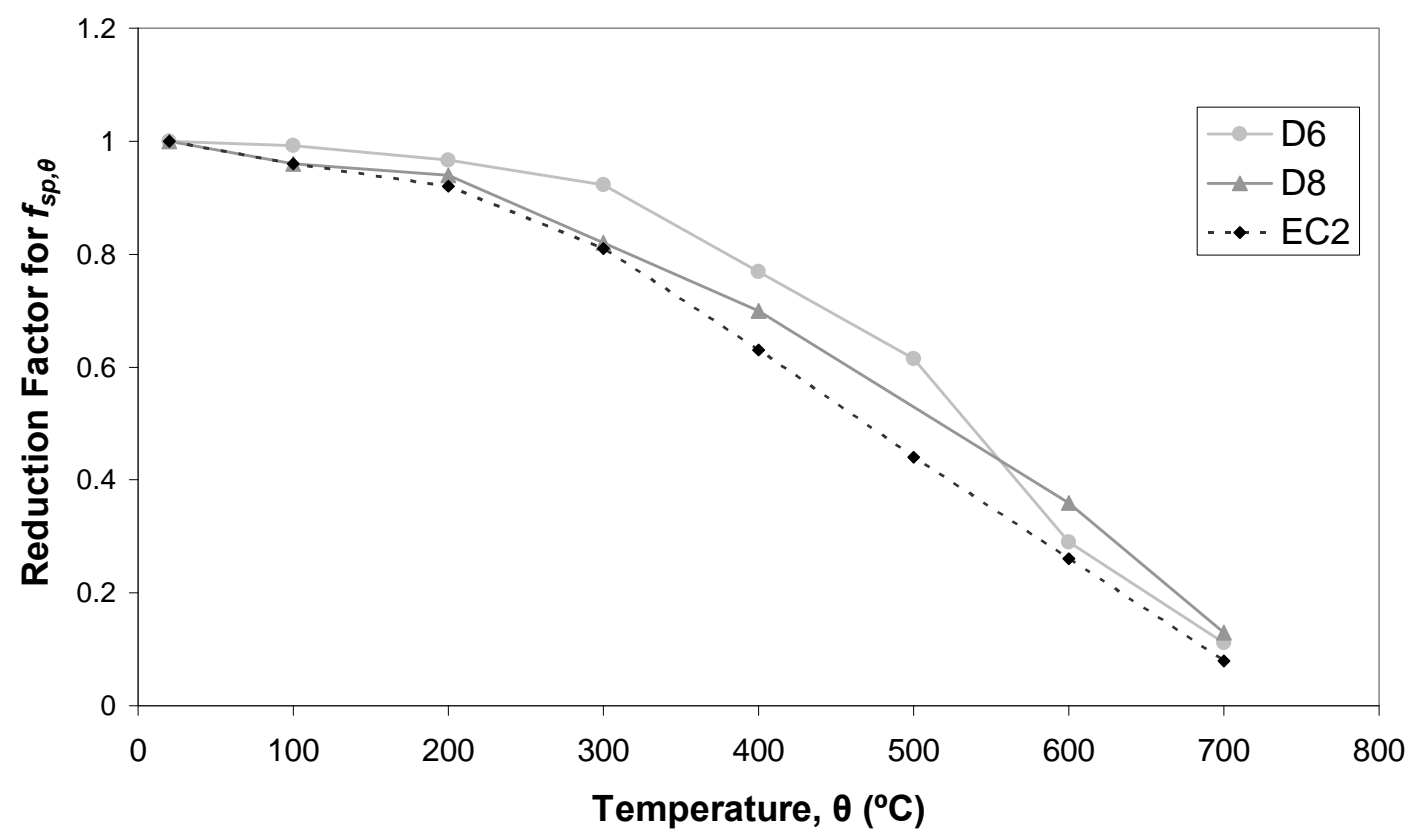

(b)

Figure 9 Effect of elevated temperature on $f_{s p, \theta}$ for (a) hot-rolled specimens and (b) cold-worked specimens 


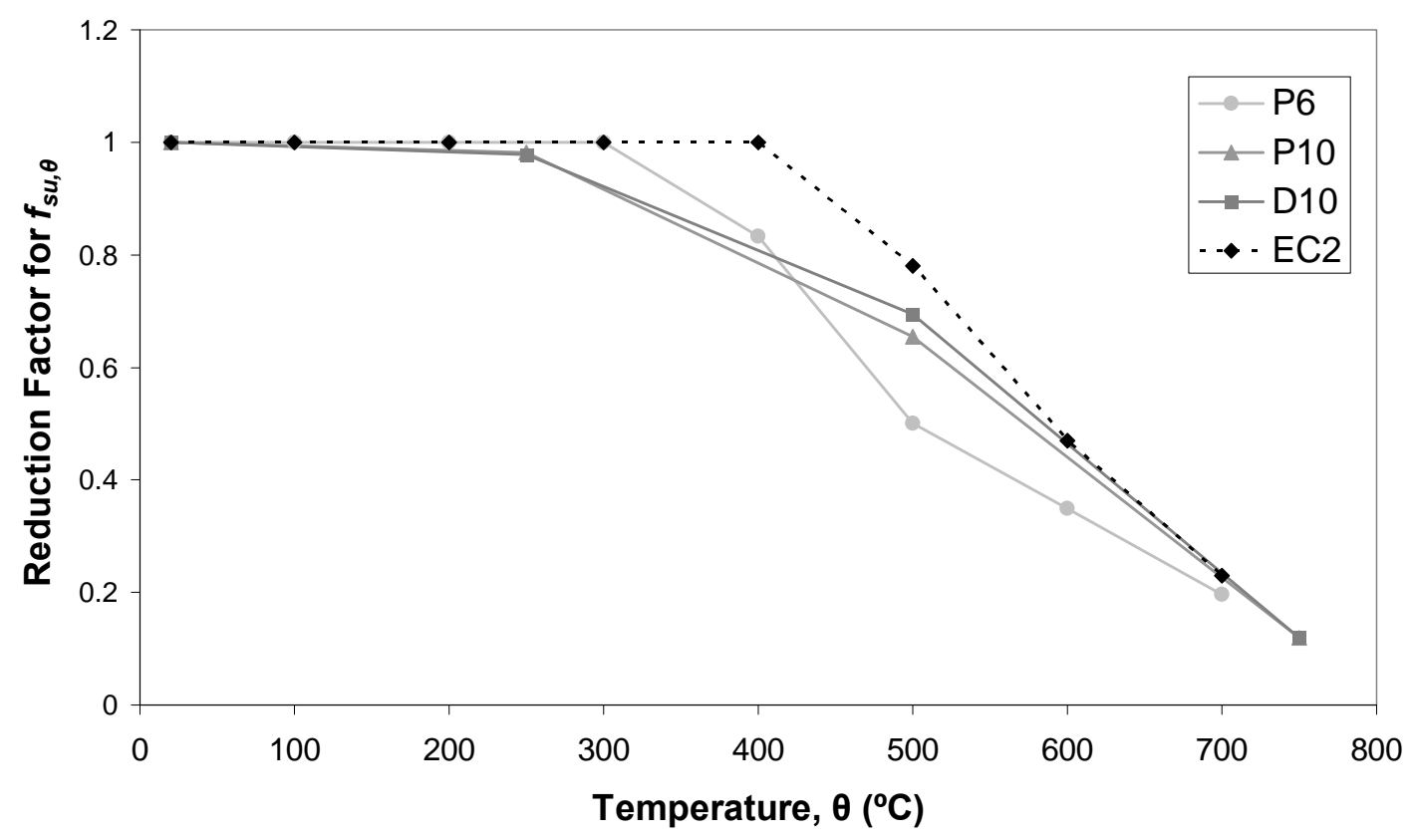

(a)

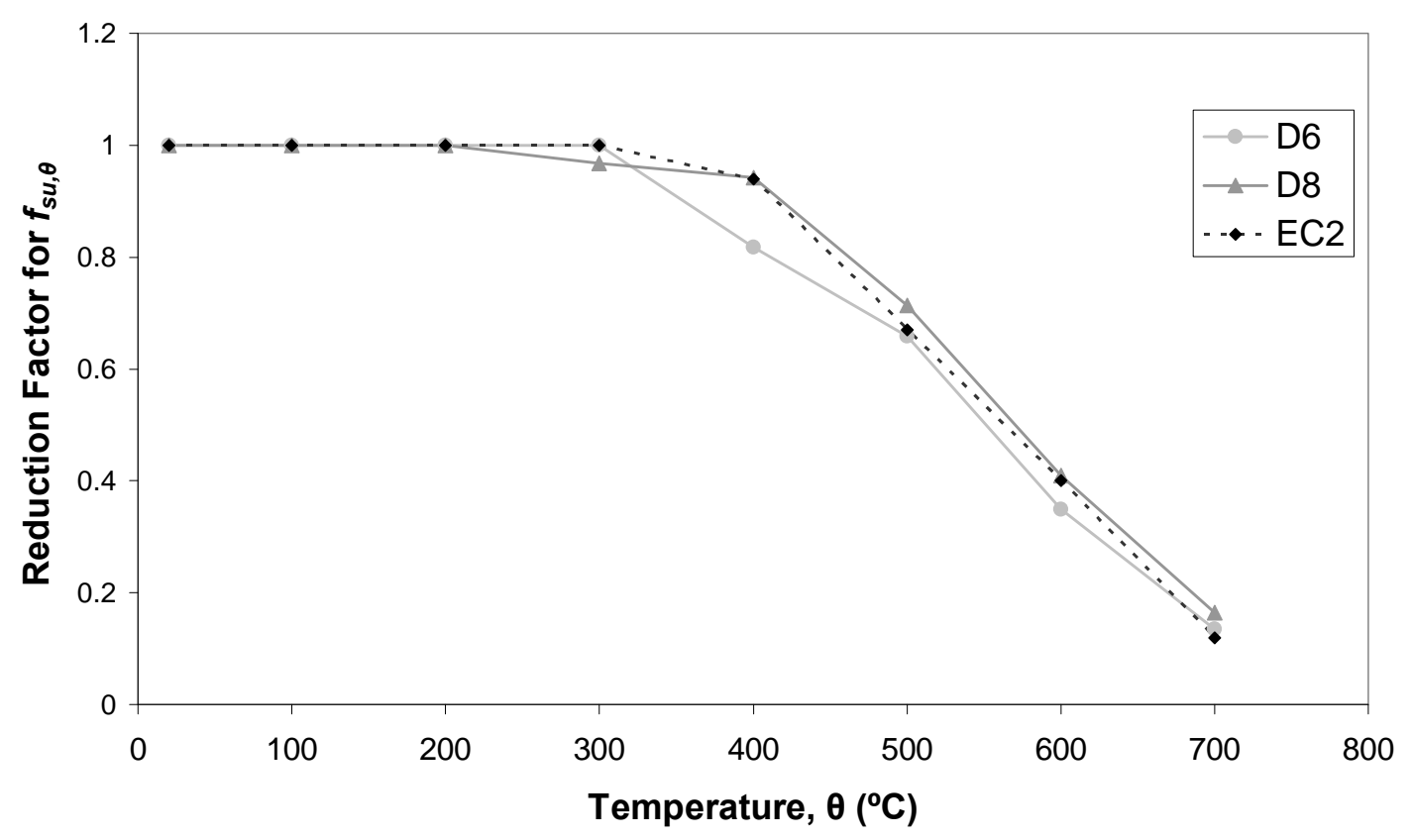

(b)

Figure 10 Effect of elevated temperature on $f_{s u, \theta}$ for (a) hot-rolled specimens and (b) cold-worked specimens 


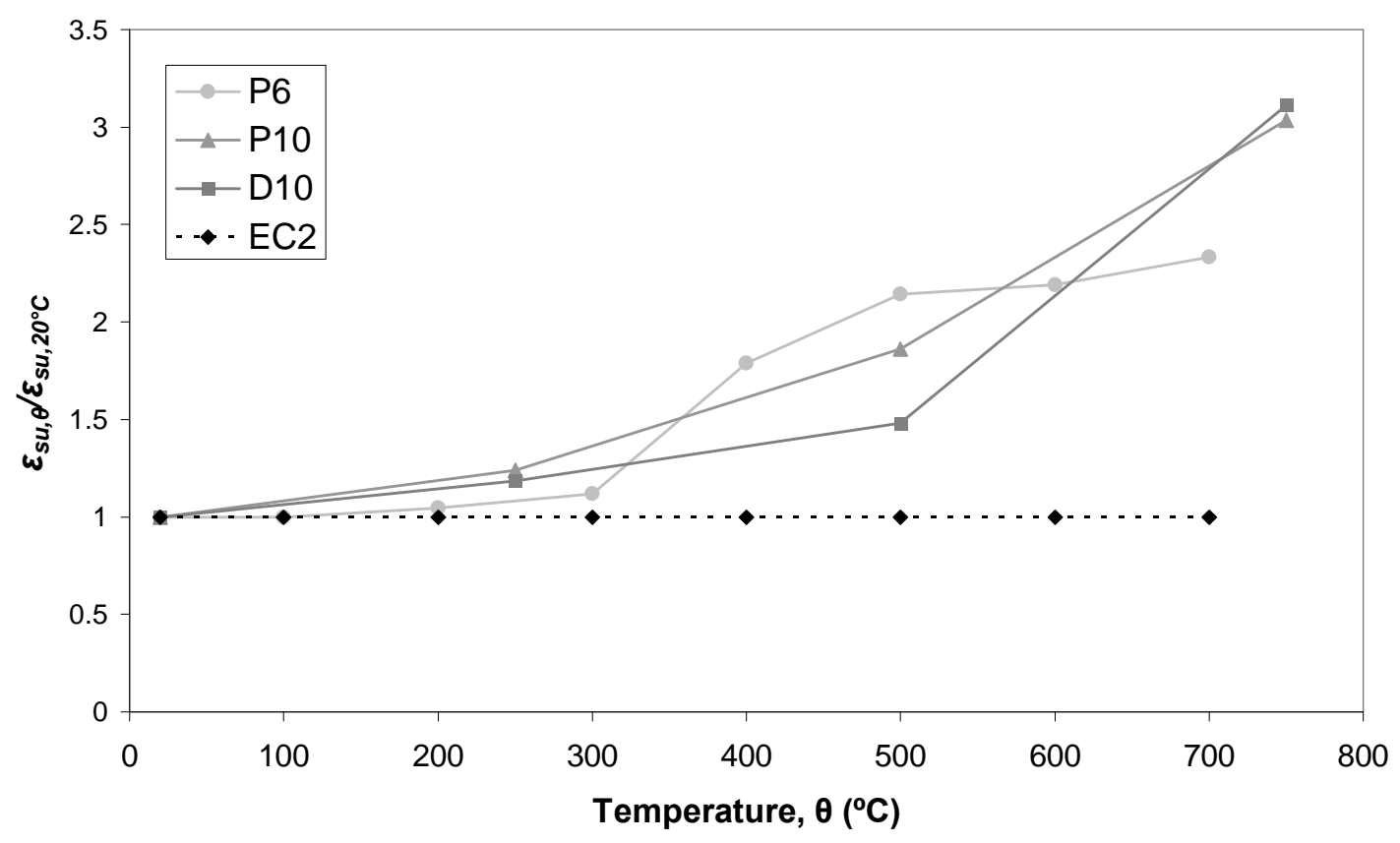

(a)

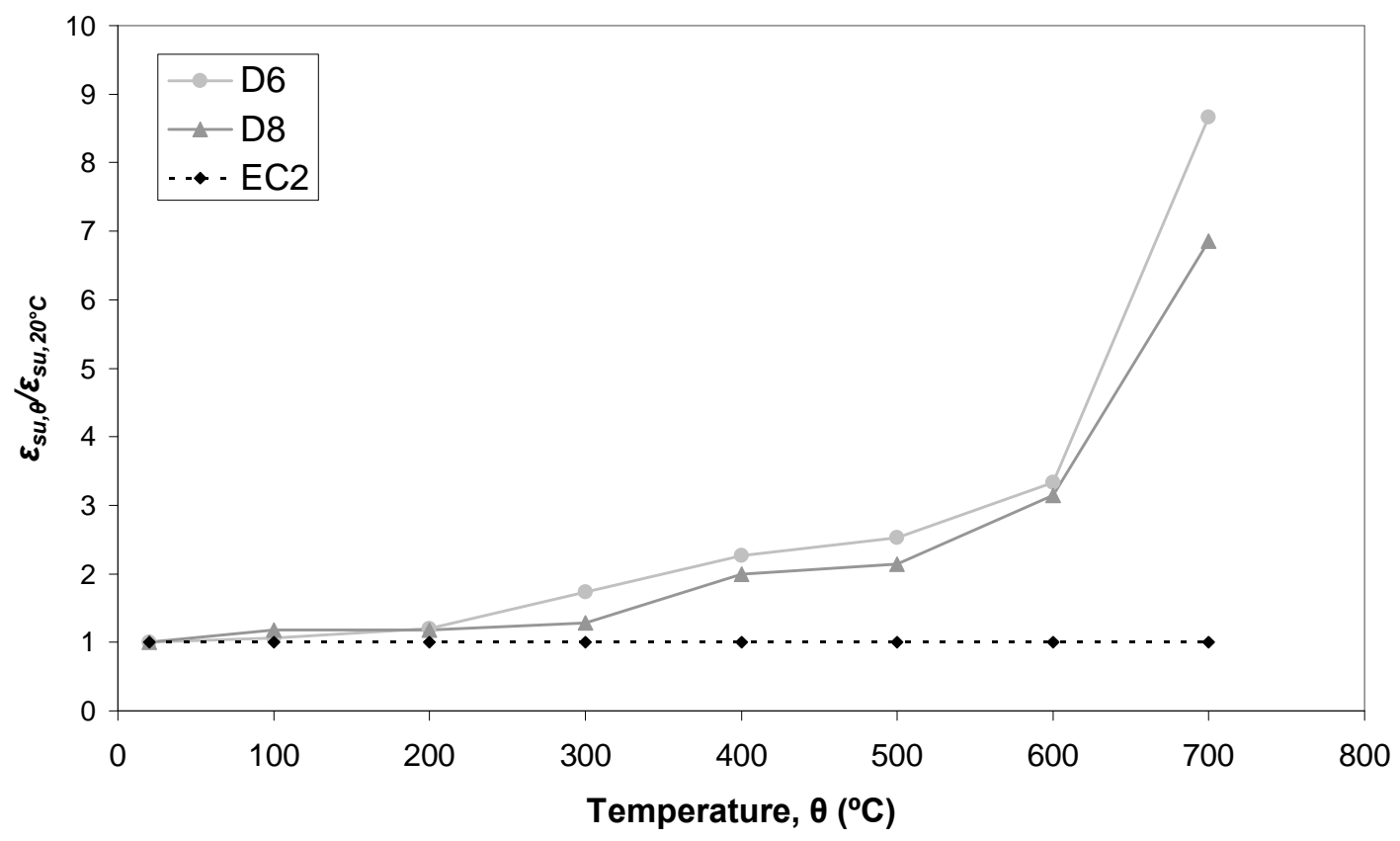

(b)

Figure 11 Effect of elevated temperature on $\varepsilon_{s u, \theta}$ for (a) hot-rolled specimens and (b) cold-worked specimens 


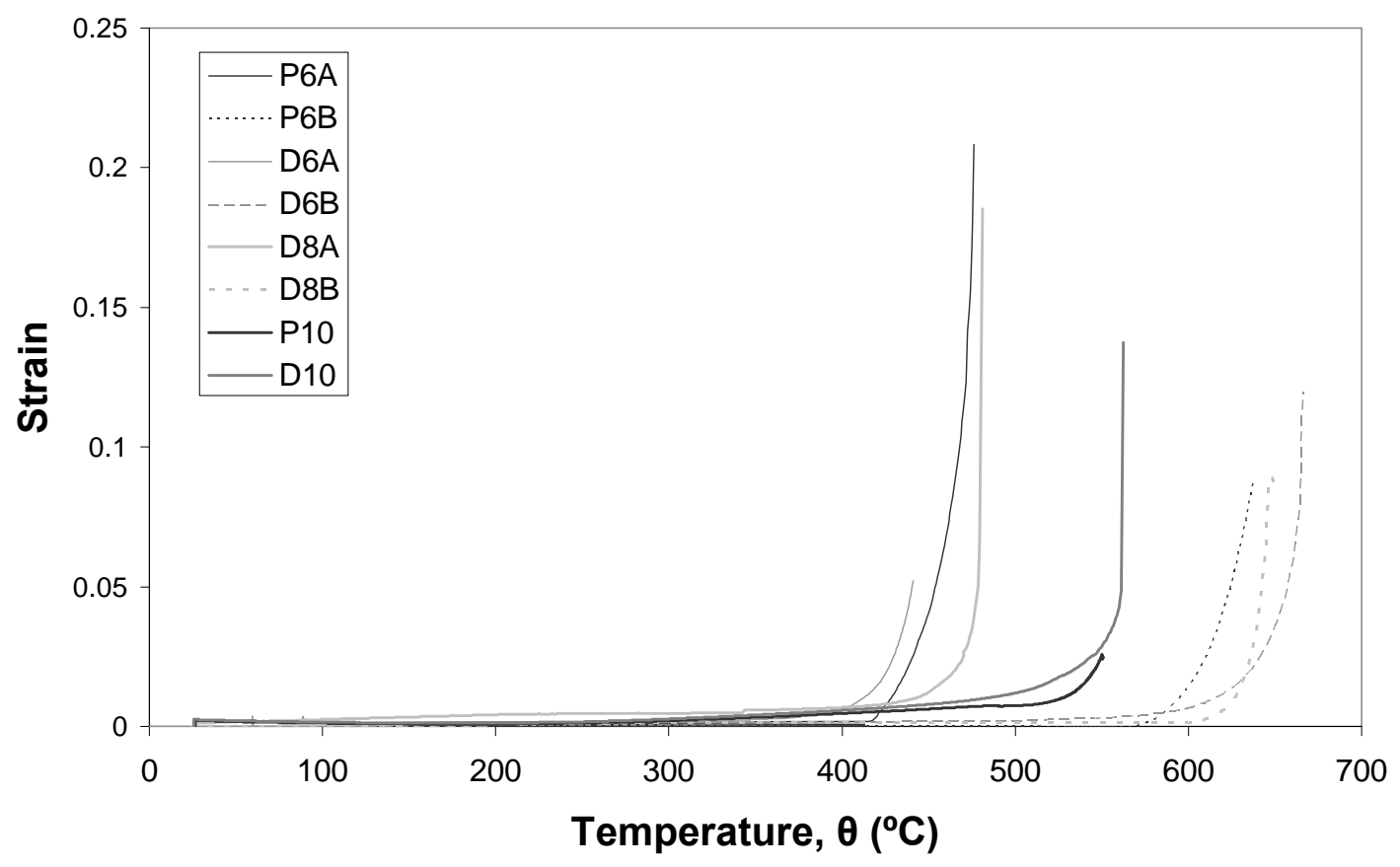

Figure 12 Transient strain variation with temperature 


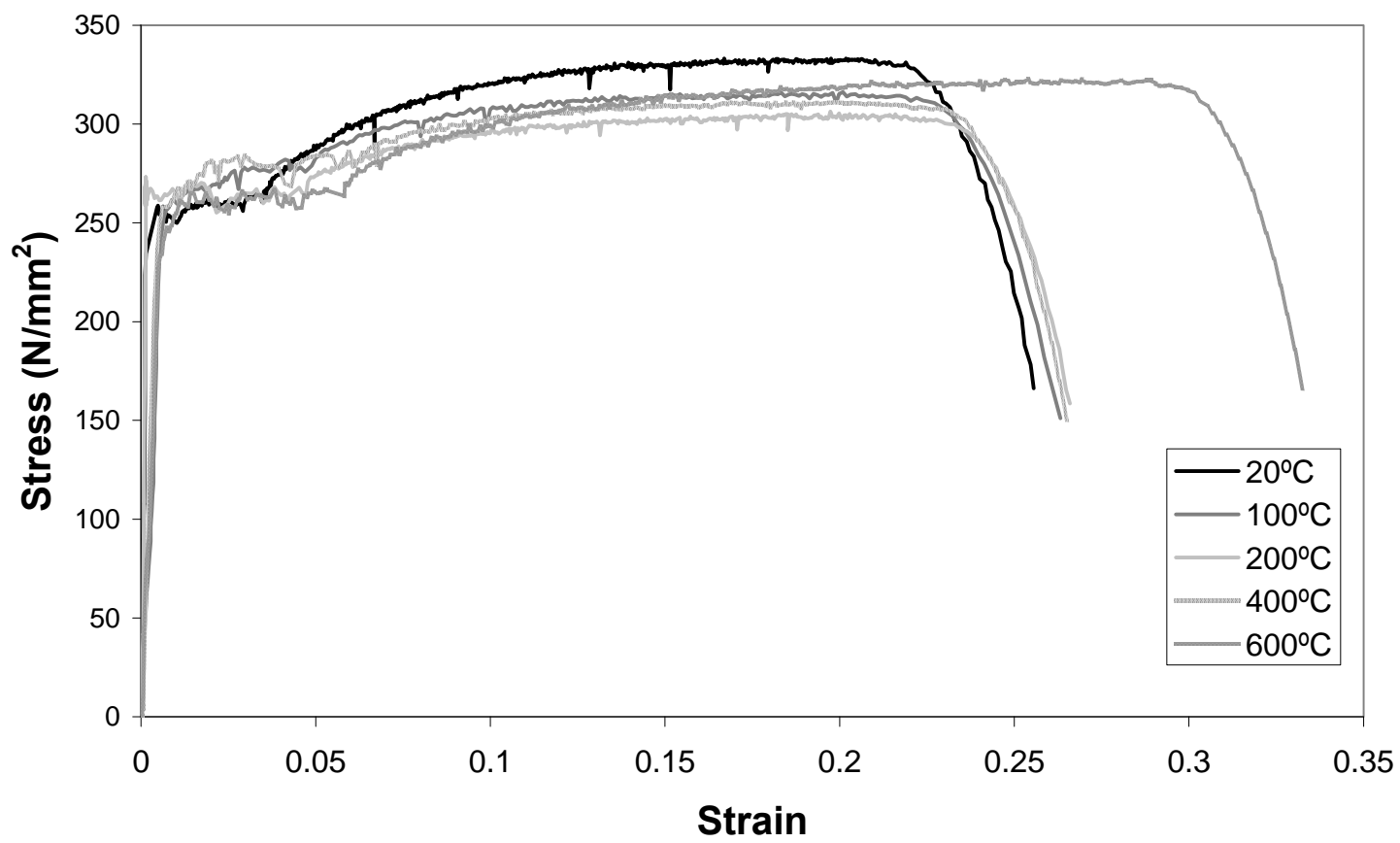

(a): P6

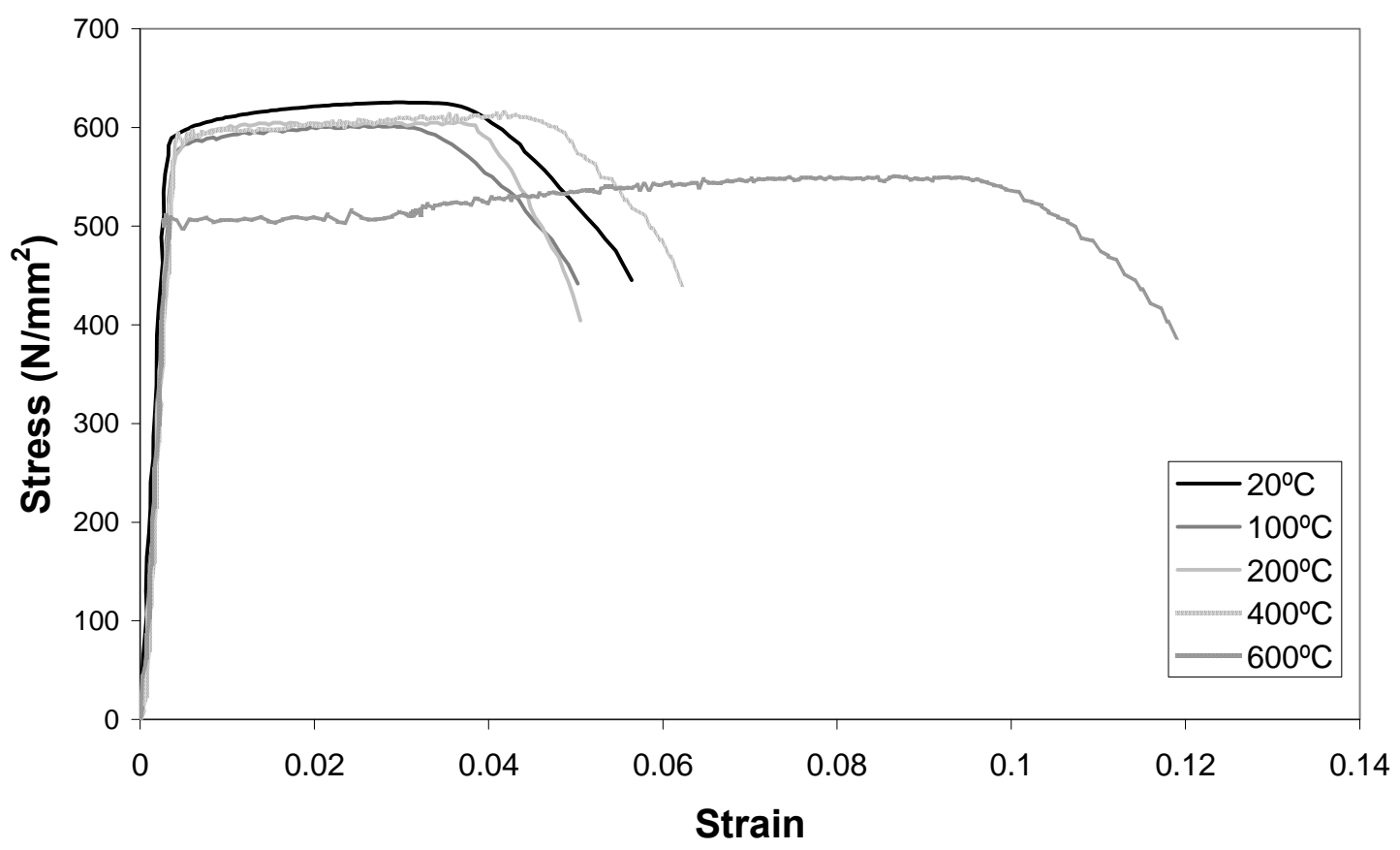

(b): D6 


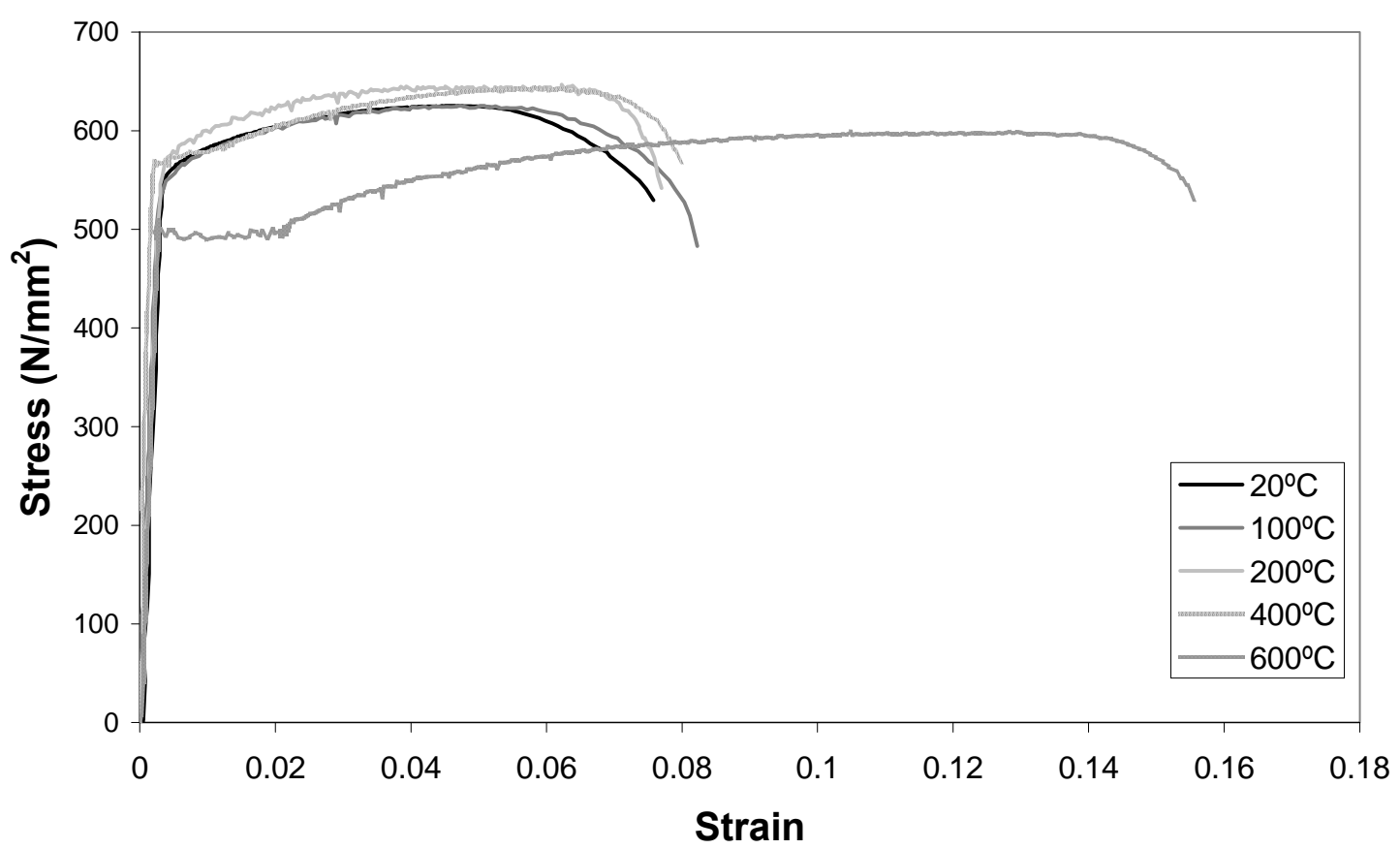

(c): D8

Figure 13 Residual mechanical properties of (a) P6; (b) D6; and (c) D8 


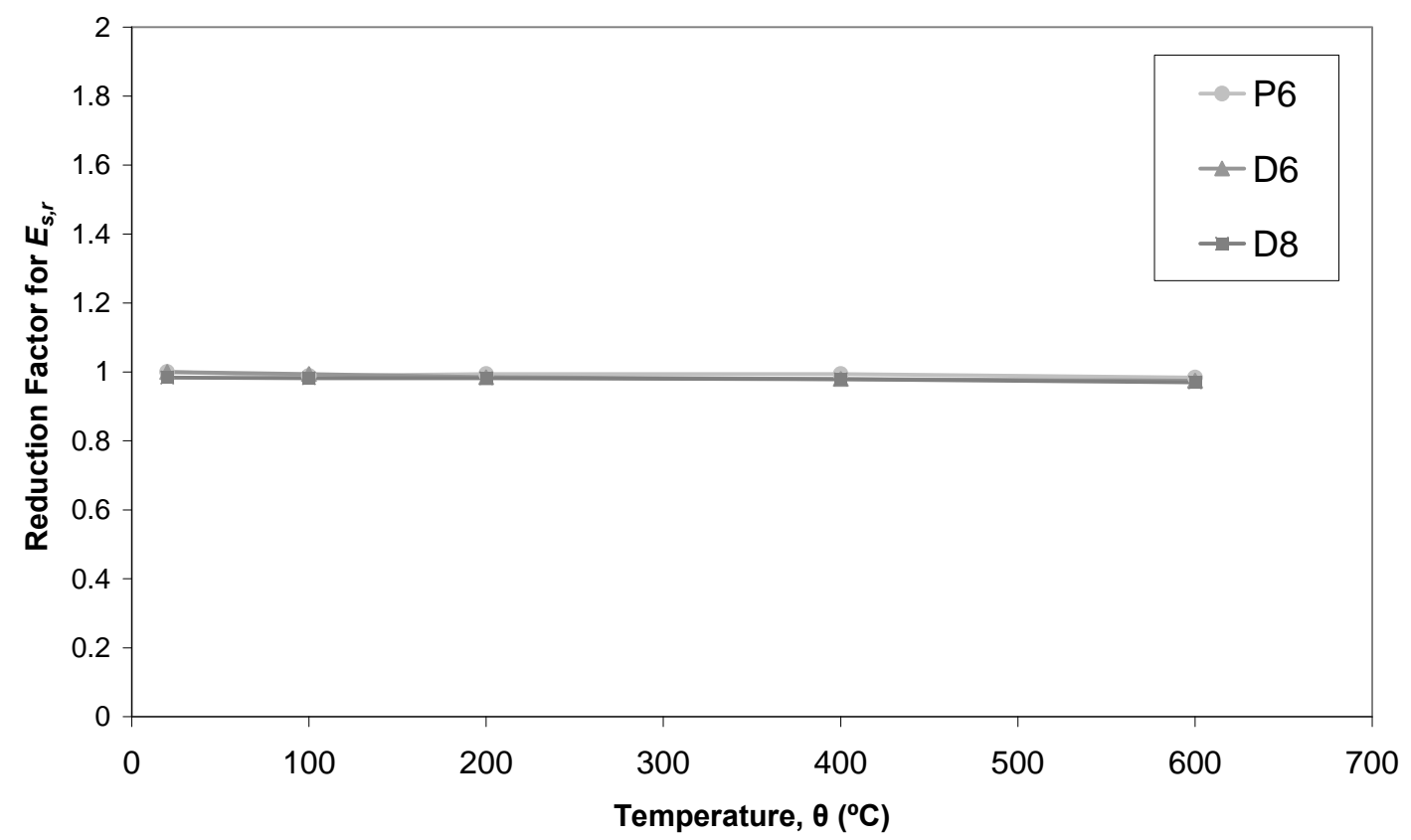

(a): $E_{s, r}$

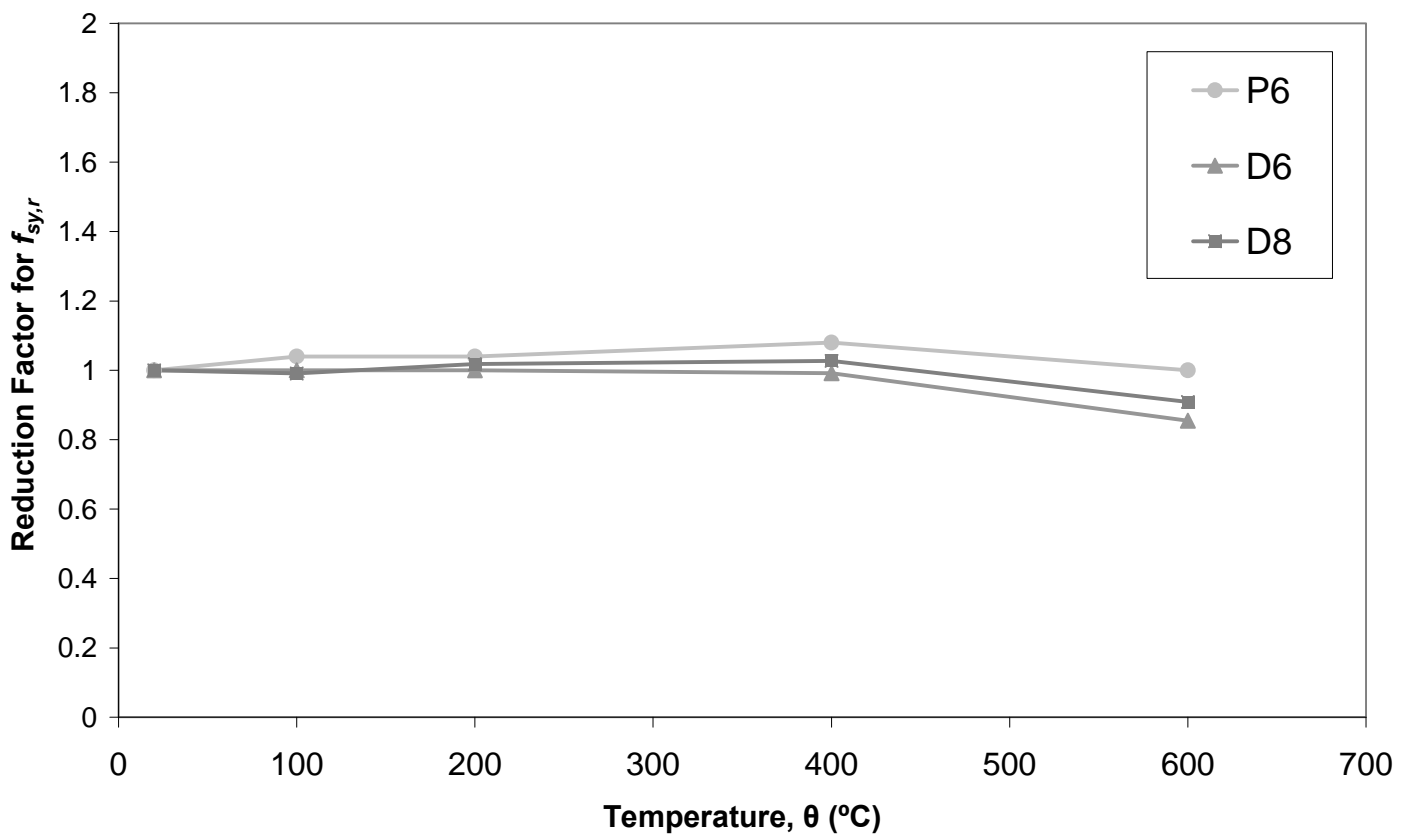

(b): $f_{s y, r}$ 


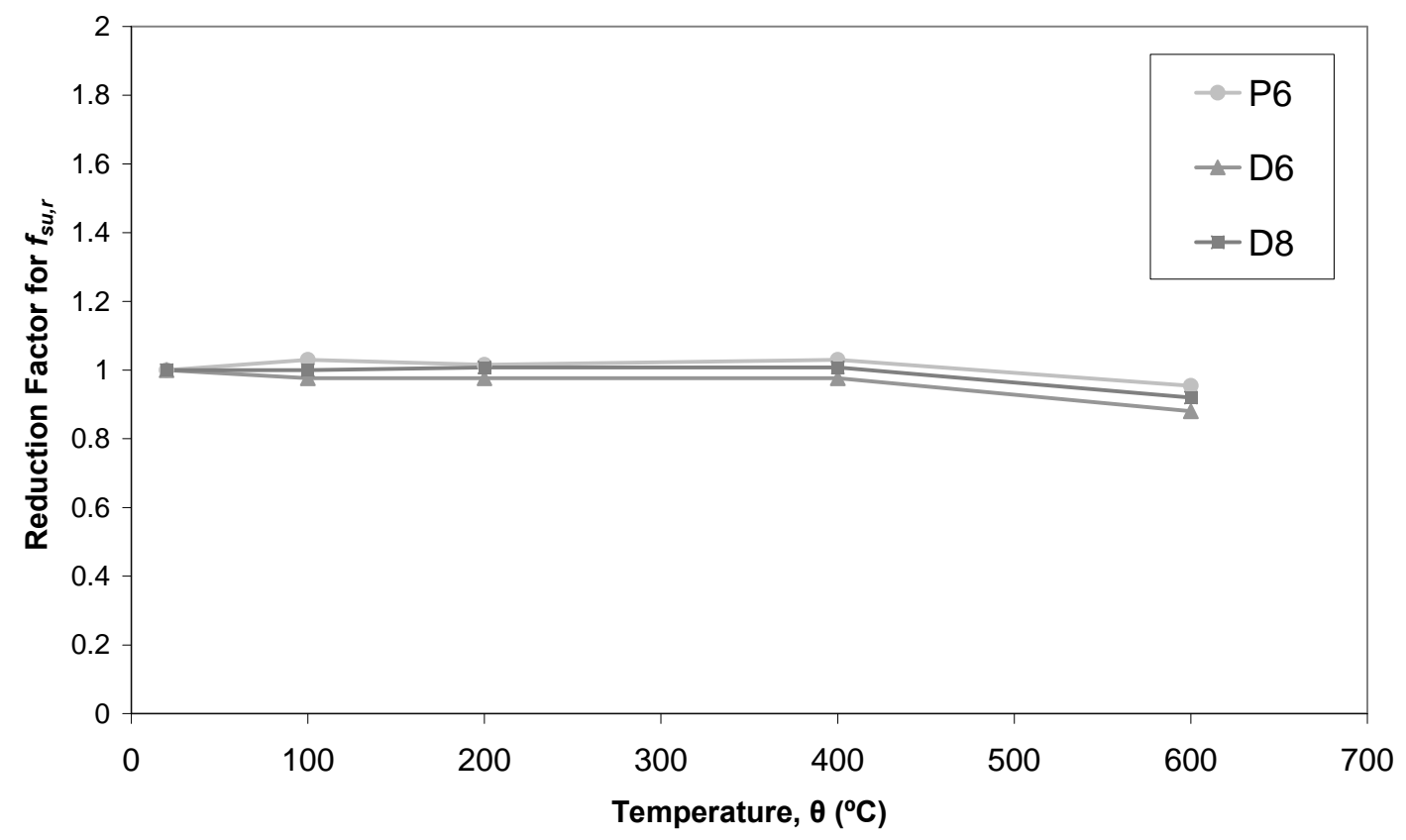

(c): $f_{\text {su,r }}$

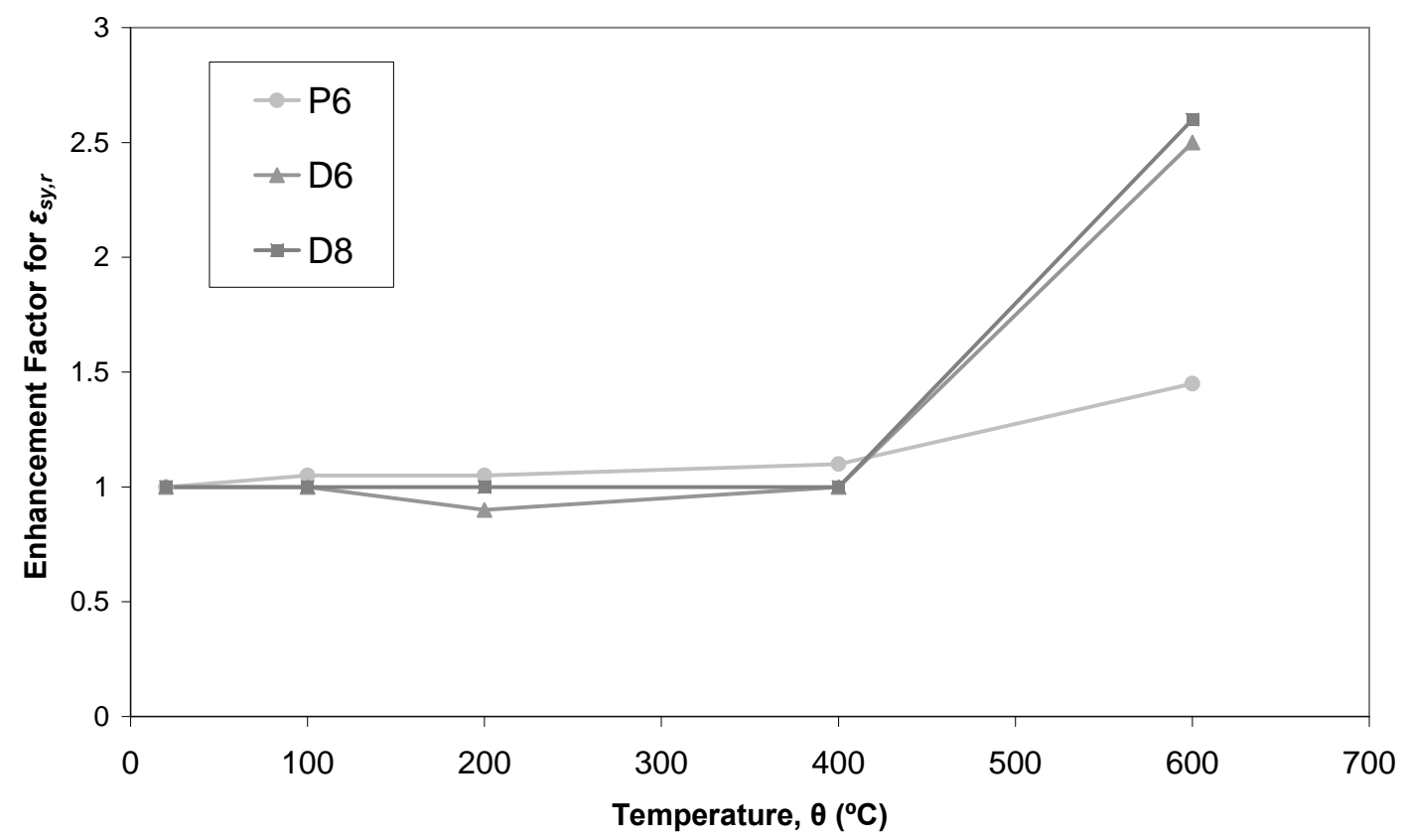

(d): $\varepsilon_{s u, r}$

Figure 14 Effect of elevated temperature on the residual properties for each bar type including (a) $E_{s, r} ;$ (b) $f_{s y, r} ;$ (c) $f_{s u, r}$; and (d) $\varepsilon_{s u, r}$ 